\title{
MATERNAL ZIKA VIRUS (ZIKV) INFECTION FOLLOWING VAGINAL INOCULATION WITH ZIKV-INFECTED SEMEN IN THE TIMED-PREGNANT OLIVE BABOON
}

Sunam Gurung ${ }^{1,4}$, Hugh Nadeau ${ }^{1,4}$, Marta Maxted ${ }^{1}$, Jamie Peregrine ${ }^{1}$, Darlene Reuter ${ }^{3}$, Abby Norris ${ }^{3}$, Rodney Edwards ${ }^{1}$, Kimberly Hyatt ${ }^{1}$, Krista Singleton ${ }^{1}$, James F. Papin ${ }^{2,3}$, Dean A. Myers ${ }^{1}$

${ }^{1}$ Department of Obstetrics and Gynecology, ${ }^{2}$ Department of Pathology, ${ }^{3}$ Division of Comparative Medicine, Oklahoma City, OK 73109, ${ }^{4}$ First and second authors contributed equally to the preparation of this manuscript.

\section{Corresponding author:}

Dean A. Myers, Ph.D.

Section of Maternal Fetal Medicine

Department of Obstetrics and Gynecology

University of Oklahoma Health Sciences Center

Oklahoma City, OK 73104

(405) 271-2286

dean-myers@ouhsc.edu 


\section{ABSTRACT}

ZIKV infection is associated with pregnancy loss, fetal microcephaly and other

47 malformations. While Aedes sp. of mosquito are the primary vector for ZIKV, sexual

48 transmission of ZIKV is a significant route of infection. ZIKV has been documented in

49 human, mouse and non-human primate (NHP) semen. It is critical to establish NHP

50 models of vertical transfer of ZIKV that recapitulate human ZIKV pathogenesis. We

51 hypothesized that vaginal deposition of ZIKV infected baboon semen would lead to

52 maternal infection and vertical transfer in the olive baboon (Papio anubis). Timed

53 pregnant baboons $(n=6)$ were inoculated via vaginal deposition of baboon semen

54 containing $10^{6} \mathrm{ffu}$ ZIKV ( $\mathrm{n}=3$, French Polynesian isolate:H/PF/2013, $\mathrm{n}=3$ Puerto Rican

55 isolate:PRVABC59) at mid-gestation (86-95 days gestation [dG]; term 183dG) on day (d)

560 (all dams), and then at 7 day intervals through three weeks. Maternal blood, saliva and

57 cervico-vaginal washes were obtained at select days post-inoculation. Animals were

58 euthanized at 28 days post initial inoculation (dpi; $n=5)$ or $39 \mathrm{dpi}(n=1)$ and maternal/fetal

59 tissues collected. vRNA was quantified by qPCR. Viremia was achieved in 3/3 FP ZIKV

60 infected dams and 2/3 PR ZIKV. ZIKV RNA was detected in cVw (5/6 dams;). ZIKV RNA

61 was detected in lymph nodes, but not ovary, uterus, cervix or vagina in the FP ZIKV

62 dams but was detected in uterus, vagina and lymph nodes. Placenta, amniotic fluid and

63 all fetal tissues were ZIKV RNA negative in the FP infected dams whereas 2/3 PR

64 infected dam placentas were ZIKV RNA positive. We conclude that ZIKV infected

65 semen is a means of ZIKV transmission during pregnancy in primates. The PR isolate

66 appeared more capable of wide spread dissemination to tissues, including placenta

67 compared to the FP strain. 


\section{IMPORTANCE}

71 Due to its established link to pregnancy loss, microcephaly and other major congenital

72 anomalies, Zika virus (ZIKV) remains a worldwide health threat. Although mosquitoes

73 are the primary means of ZIVK transmission, sexual transmission in human populations

74 is well documented and provides a means for widespread dissemination of the virus.

75 Differences in viremia, tissue distribution, immune responses and pregnancy outcome

76 from sexually transmitted ZIKV compared to the subcutaneous route of infection are

77 needed to better clinically manage ZIKV in pregnancy. Through our previous work, we

78 have developed the olive baboon as a non-human primate model of ZIKV infection that

79 is permissible to ZIKV infection via the subcutaneous route of inoculation and transfer of

80 ZIKV to the fetus in pregnancy. The current study evaluated the course of ZIKV infection

81 after vaginal inoculation of ZIKV in pregnant baboons at mid-gestation using baboon

82 semen as the carrier and comparing two isolates of ZIKV, the French Polynesian isolate

83 first associated with microcephaly and the Puerto Rican isolate, associated with an

84 increased risk of microcephaly observed in the Americas. 


\section{INTRODUCTION}

The propagation of Zika virus (ZIKV) represents a worldwide reproductive health

94 crisis given the virus's geographic distribution and severity of its effect on the developing

95 fetus. At its peak, ZIKV infection was being reported in more than 60 countries $(1,2)$.

96 While ZIKV infection is usually mild or asymptomatic with typical symptoms that include

97 fever, rash, and conjunctivitis, the impact of ZIKV on the developing fetus can be severe,

98 including microcephaly and associated neurological damage, fetal growth restriction,

99 intrauterine fetal demise, spontaneous abortion as well as other congenital anomalies

100 now termed collectively as Congenital Zika Syndrome (CZS). The impact of ZIKV

101 infection on the fetus led to worldwide interest in the virus following the major outbreak in

102 Brazil in $2015(3)$.

103 While the Aedes species of mosquitos are the primary means of ZIKV

104 transmission, sexual transmission of ZIKV is now well documented in the human

105 population (4-8) and a greater incidence of ZIKV in females of a sexually active age (9)

106 suggesting sexual transmission as a causative factor. Sexual transmission in humans

107 was first reported in 2008 (10) and from 2015-2018, 52 cases of sexually transmitted

108 ZIKV were reported in the United States (11). Sexual transmission of ZIKV has been

109 described from a male to pregnant female as well $(12,13)$. ZIKV RNA and infectious

110 virus have been detected in human semen, considerably longer than detection in blood,

111 saliva and urine (6). ZIKV RNA has been detected in semen at 188 days post-onset of

112 symptoms, while infectious ZIKV has been observed in human semen up to 69 days

113 post-symptoms $(8,14)$. We recently demonstrated ZIKV RNA in semen in male baboons

114 up to 41 days post infection which was when the study was terminated and persistence

115 of ZIKV RNA in the male reproductive tissues after systemic resolution of the virus thus

116 confirming findings in human population (15). Male to female sexual transmission of 
117 ZIKV has been observed in an interferon deficient (AG129) mouse model of ZIKV

118 infection, resulting in a high degree of infection of AG129 females, including vertical

119 transfer. In addition, vaginal ZIKV inoculation resulted in a high degree of infection in

120 both non-pregnant and pregnant AG129 females. Yockey et al (16) similarly found that

121 ZIKV replicated in the vaginal mucosa of wild type mice and while not leading to viremia,

122 did result in fetal growth restriction and infection of the fetal brains indicating that vaginal

123 inoculation may lead to direct transfer of the virus to the intrauterine compartment

124 through a compromised cervical canal or via local lymphatics to the utero-placental

125 interface. Vaginal inoculation of non-pregnant female Rhesus monkeys with ZIKV has

126 also been achieved, albeit using raw virus in culture media diluent rather than semen in

127 the inoculant. A recent study suggested that human semen may actually inhibit ZIKV

128 infectivity in an in vitro setting, including human reproductive tract explants (17).

129 Studies estimate sexual transmission of ZIKV in human population to be responsible for

130 substantial number of infections and maintenance of virus in human population with or

131 without the presence of the vector. This is particularly of concern in pregnant women as

132 studies have shown ZIKV to be disseminated to placenta and fetus after intravaginal

133 infections and cause CZS in fetus $(7,16,18-20)$. Sexual transmission is also a likely

134 means for the global spread of the virus between land masses.

136 of ZIKV in the blood, saliva, cervico-vaginal washings, and in maternal reproductive and

137 fetal tissues following intravaginal inoculation using ZIKV containing semen in baboons

138 at mid-gestation. In addition, we compared responses to both French Polynesian and

139 Puerto Rican ZIKV isolates to assess for differences in virulence, tissue tropism and

140 vertical transfer. Although the initial link between vertical transfer of ZIKV and

141 microcephaly was first described in the French Polynesian outbreak after post-hoc 
142 analysis, a dramatic increase in microcephaly and CZS was observed in Brazil and other

143 tropical American regions including Puerto Rico. Although an initial examination of

144 isolates found a single point mutation in the FP isolate to likely contribute to

145 neuroprogenitor cell targeting by ZIKV and potentially vertical transfer mechanisms,

146 American isolates have accumulated further mutations and thus may render a more

147 severe pregnancy outcome. This study targets many gaps in current knowledge about

148 viremia and pregnancy outcome due to ZIKV infection transmitted sexually in a highly

149 relevant non-human primate, the Olive Baboon.

150

151

152

153

154

155

156

157

158

159

160

161

162

163

164

165

166

167

168

169

\section{MATERIALS AND METHODS}

\section{Ethical Statement}

All experiments utilizing baboons were performed in compliance with guidelines established by the Animal Welfare Act for housing and care of laboratory animals as well as the United States National Institutes of Health Office of Laboratory Animal Welfare Public Health Service Policy on the Humane Care and Use of Laboratory Animals in Assessment and Accreditation of Laboratory Animal Care (AAALAC) International and National accredited laboratories. All experiments were conducted in accordance with and approval from the University of Oklahoma Health Sciences Center Institutional Animal Care and Use Committee (IACUC; protocol no. 101523-16-039-I). All studies with ZIKV infection were performed in Assessment and Accreditation of Laboratory Animal Care (AAALAC) International accredited ABSL2 containment facilities at the OUHSC. Baboons were fed standard monkey chow twice daily as well as receiving daily food supplements (fruits). Appropriate measures were utilized to reduce potential distress, pain and discomfort. Ketamine $(10 \mathrm{mg} / \mathrm{kg}$ ) was used to sedate baboons during 
170 all procedures, which were performed by trained personnel. All animals received

171 environmental enrichment. ZIKV infected animals were caged separately but within

172 visual and auditory contact of other baboons to promote social behavior and alleviate

173 stress. At the designated times post inoculation, the animals were euthanized according

174 to the recommendations of the American Veterinary Medical Association (2013 panel on

175 Euthanasia).

177 Animals

178 Adult timed-pregnant female olive baboons $(n=6)$ were utilized for this study. All

179 females were multiparous with history of successful prior pregnancies. All dams used in

180 this study were determined to be seronegative for West Nile Virus (21).

182 Virus stocks, infection and sample collection

183 Animals were anesthetized with an intramuscular dose of Ketamine (10 mg/kg) before all

184 procedures (viral inoculation, blood, salivary swabs and cervico-vaginal washing

185 collection). Timed-pregnant female baboons were infected vaginally with a dose of $10^{6}$

186 focus forming units (ffu; $1 \mathrm{ml}$ volume per dose) of the baboon semen-spiked with the

187 French Polynesian ZIKV isolate (H/PF/2013) or the Puerto Rican ZIKV isolate

188 (PRVABC59) placed at the cervical os using a speculum to aid with deposition. Semen

189 samples were collected by rectal probe ejaculation as previously described for our

190 laboratory (15) from total of 11 male baboons seronegative for WNV and ZIKV and

191 stored immediately at $-80^{\circ} \mathrm{C}$. Each semen aliquot was thawed on ice before adding virus

192 to it for vaginal infection. Semen samples were chosen at random per inoculation.

193 Inoculations were repeated every 7 days until ZIKV RNA was detected in whole blood by 
194 qPCR, or in one dam that never became viremic, through 4 weekly inoculations. The

195 dosage used to infect the animals in our study is based on the previous works done in

196 mosquitoes carrying WNV and DENV, where it was estimated that mosquitoes carry

$1971 \times 10^{4}$ to $1 \times 10^{6}$ plaque forming units (PFU) of the virus (22), from a study evaluating

198 Brazilian ZIKV in a bite from Aedes aegypti mosquito and from a study of mosquito

199 transmission of ZIKV in rhesus monkeys (23). The pregnant females were infected near

200 mid-gestation (between 86 and 95 days of gestation [dG]; term is approx. $181 \mathrm{dG}$ ).

201 Maternal blood and saliva samples were obtained on the day of inoculation (day 0) as

202 well as at $4,7,11,14,21$, and 28 days post infection (dpi). Cervico-vaginal washings

203 were completed utilizing $3 \mathrm{~mL}$ of normal saline loaded into a $5 \mathrm{~mL}$ syringe with a

204 catheter tip then injected onto the cervix and posterior vaginal fornix and subsequently

205 recollected. These were obtained on days -4 (pre-wash), 4, 11, 14, 21, and 28 post

206 infection. Ultrasound evaluation of fetal viability was completed with each inoculation and

207 inter-inoculation specimen collection. Whole blood was collected into EDTA tubes.

208 Saliva and vaginal samples were collected by cotton roll salivette. The sampling

209 procedure for each dam is detailed in Table 1.

210 At the end of the study for each animal, dams were sedated with ketamine, all maternal

211 samples obtained as well as ultrasound measurements, then the animal rapidly

212 euthanized with euthasol. A C-section was quickly performed, cord blood obtained and

213 the fetus euthanized with euthasol. Maternal and fetal tissues were rapidly collected and

214 samples were both fixed with $4 \%$ paraformaldehyde and frozen on dry ice (stored at -

$\left.21580^{\circ} \mathrm{C}\right)$ for each tissue.

216 Complete blood counts (CBCs)

217 CBCs were obtained for all females on EDTA-anticoagulated whole blood samples

218 collected on day 0 and subsequent days-post infection as shown in the experimental 
219 timeline (Idexx ProCyte DX hematology analyzer; Idexx laboratories, ME). CBCs

220 included analysis for red blood cells (RBCs), hemoglobin, hematocrit and platelet count.

222 One-step quantitative reverse transcription PCR

223 Primers and probes used for qRT-PCR were designed by Lanciotti et al (24) (Table 2).

224 RNA was isolated from maternal and fetal tissues (Table 3 and 4) using QIAamp cador

225 pathogen mini kit (Qiagen, Valencia, CA). ZIKV RNA was quantitated by one-step

226 quantitative real time reverse transcription PCR using QuantiTect probe RT-PCR kit

227 (Qiagen) on an iCycler instrument (BioRad). Primers and probes were used at a

228 concentration of $0.4 \mu \mathrm{M}$ and $0.2 \mu \mathrm{M}$ respectively and cycling conditions used were $50^{\circ} \mathrm{C}$

229 for $30 \mathrm{~min}, 95^{\circ} \mathrm{C}$ for $15 \mathrm{~min}$ followed by 40 cycles of $94^{\circ} \mathrm{C}$ for $15 \mathrm{~s}$ and $60^{\circ} \mathrm{C}$ for $1 \mathrm{~min}$.

230 Concentration of the viral RNA (copies/milliliter) was determined by interpolation onto a

231 standard curve of six 10 -fold serial dilutions $\left(10^{6}\right.$ to $10^{1}$ copies $\left.\left./ \mathrm{ml}\right)\right)$ of a synthetic ZIKV

232 RNA fragment available commercially from ATCC (ATCC VR-3252SD). The cutoff for

233 limit of detection of ZIKV RNA was $1 \times 10^{2}$.

\section{ZIKV ELISA}

235 ZIKA specific IgM and IgG antibody responses were assessed in the serum samples

236 using the commercially available anti-ZIKV IgM (\#ab213327, Abcam, Cambridge, MA)

237 and IgG (\#Sp856C, XpressBio, Fredrick, MD) ELISA kits. Briefly, a 1:100 for IgM and

$238 \quad 1: 50$ for IgG serum dilution was performed in duplicate and added to the pre-coated

239 plates available in the kits. The assays were performed using the manufacturer's

240 instructions and the assay was read at $450 \mathrm{~nm}$ for $\operatorname{lgM}$ and $405 \mathrm{~nm}$ for $\lg \mathrm{G}$ antibodies in

241 the serum. 
244 For IF, slides were baked for one hour at $56^{\circ} \mathrm{C}$, deparaffinized, and HIER was performed

245 in the Retriever 2100 with R-Universal Epitope Recovery Buffer (62719-10 lot 180314.

246 After retrieval, slides were blocked in 5\% normal donkey serum for 1 hour, then primary

247 antibodies in $0.5 \%$ normal serum were added and incubated overnight, humidified, at

$248 \quad 4^{\circ} \mathrm{C}$ [MAC-387, macrophage antibody (Abcam, MA); Pan anti-flavivirus; (Millipore, CA)].

249 The next morning slides were removed from $4^{\circ} \mathrm{C}$ and allowed to equilibrate to RT,

250 covered, on the benchtop for 1 hour. Slides were rinsed $4 \times 5$ minutes with PBS, then

251 secondary antibodies were added and incubated 1 hour, covered, at RT. Donkey anti-

252 mouse IgG F(ab')2 AlexaFluor 594 (Jackson Immunolabs) was used as secondary

253 antibody. Slides were rinsed in PBS, counterstained 5 minutes with DAPI in PBS and

254 cover slipped using Shur/Mount. Cover glass were sealed with nail polish and slides

255 were stored at $4^{\circ} \mathrm{C}$ and visualized using a fluorescent microscope (Olympus BX40).

256 Images were captured using CellSens imaging software (Olympus).

\section{RESULTS}

\section{Description of animal cohorts and experimental outline}

For this study, adult timed pregnant female olive baboons $(n=6)$ were used. All baboons

264 were infected via vaginal inoculation with a clinically relevant dose $\left(1 \times 10^{6} \mathrm{pfu}\right)$ of the

265 French Polynesian (H/PF/2013) or the Puerto Rican (PRVABC59) ZIKV isolate. Blood,

266 saliva, and cervico-vaginal washings were collected as shown in Table 1. In the FP

267 cohort, 2/3 dams developed slight to negligible rash on the abdomen and in the inguinal

268 and axillary regions and no conjunctivitis. One FP dam (FP1) presented with moderate

269 rash on the abdomen, in the bilateral axillary and inguinal regions and mild

270 conjunctivitis. In the PR cohort, 2/3 dams developed slight to negligible rash on the 
271 abdomen and in the axillary/inguinal regions and only one dam (PR3) developed slight

272 conjunctivitis. None of the animals showed signs of any other clinical disease. Baboons

273 were euthanized at $28 \mathrm{dpi}$. Complete blood counts (CBCs) were evaluated for all

274 females on EDTA-anticoagulated whole blood samples collected on day 0 and

275 subsequent days post infection as shown in Table 1 (Idexx ProCyte DX hematology

276 analyzer; Idexx laboratories, ME). RBC, hemoglobin and hematocrit numbers did not

277 show any differences pre-and post ZIKV infection in all females (data not shown).

278 Platelet counts did not change in response to ZIKV infection in any dam (data not

279 shown).

280

281

282

283

284

285

286

287

288

289

290

291

292

293

294

295

296

297

\section{Viral load data post infection in whole blood and saliva}

Viral RNA was quantified by one-step qRT-PCR in RNA extracted from the blood and saliva samples. ZIKV RNA was detected in the blood of all animals infected with the FP isolate of ZIKV and two of the three animals infected with the PR isolate of ZIKV (Figure 1). Among the dams infected with the FP ZIKV isolate, ZIKV RNA was detected in the blood of all three dams, with dam FP1 viremic at 7 and $11 \mathrm{dpi}$, dam FP2 viremic at 4 and 7 dpi and dam FP3 viremic at 4 and 7 dpi (Figure 1A). Among the dams infected with the PR ZIKV isolate, ZIKV RNA was detected in the blood of 2 of 3 dams; dam PR1 was viremic at 7, 11, 14 and $28 \mathrm{dpi}$, dam PR2 was viremic on 4, 7 and 14 dpi. ZIKV RNA was never detected in the blood of dam PR3 at any time point examined $(4,7,11,14$, 21, 28 or 35 dpi) (Figure 1B).

In the two dams infected with the FP ZIKV isolate, ZIKV RNA was detected in the saliva at 11 and $14 \mathrm{dpi}$ (FP1) and on $11 \mathrm{dpi}$ (FP2) (Figure 1C). In the two animals infected with the PR ZIKV isolate, ZIKV RNA was detected in the saliva at $11 \mathrm{dpi}$ (PR1) and 7 and 14 dpi (PR2) (Figure 1D). 
300 ZIKV RNA was detected in the CVW of all three dams infected with the FP isolate of

301 ZIKV and two of the three dams infected with the PR isolate of ZIKV. ZIKV RNA was

302 detected in the CVW at 4, 11, 14, 21 and 28 dpi in dam FP1, 11 and 14 dpi in dam FP2

303 and 4 and 14 dpi in dam FP3 (Figure 1E). In the PR ZIKV infected dams, two had ZIKV

304 RNA in the CVW; 4, 11, 14, 21 and 28 dpi for PR1 and 14 and 21 dpi for dam PR2

305 (Figure 1F).

\section{ZIKV RNA in maternal tissues}

308 In maternal reproductive tissues (uterus, cervix, vagina, ovaries), ZIKV RNA was not

309 detected in any of the animals inoculated with the FP ZIKV isolate. ZIKV RNA was

310 detected in the uterus of two of the animals inoculated with the PR isolate (dams PR1, 2)

311 and in the vagina of two dams (PR1, 3). ZIKV RNA was present in all of the maternal

312 lymph nodes assessed (axial, mesenteric, inguinal) except for the mesenteric nodes of

313 dam FP3 and the axial lymph nodes of dam PR3 (Table 3).

317 ZIKV RNA was not detected in any of the fetal tissues (cord blood, cortex, cerebellum,

318 umbilical cord, fetal membranes, spleen, lung, liver, eye, gonads, stomach, intestine,

319 and optic nerve; data not shown).

320 Placentas from each dam were sampled from six different locations (different

321 cotyledons). In the animals infected with the FP ZIKV isolate, ZIKV RNA was not

322 detected in any cotyledons sampled. In the animals infected with the PR isolate, ZIKV

323 RNA was detected in two of the animals (PR1, 2). In one of these animals, ZIKV RNA 
324 was detected in five cotyledons sampled (PR1), and in the other animal, ZIKV RNA was

325 detected in four cotyledons sampled (PR2) (Table 4).

\section{ZIKV antibody response}

ZIKV IgM was detected in sera of 2 of 3 FP ZIKV isolate infected dams (FP1, 2) on day

33014 and in sera of dam FP3 by day 21 post infection (Figure 2A). ZIKV IgM was detected

331 in 2 of 3 PR isolate dams $(P R 1,2)$ by day 11 post infection and in dam PR3 on day 18

332 post infection (Figure 2B). ZIKV IgG was detected in sera of dams FP 1 and 2 on day 21

333 and by day 35 post infection in the sera of dam FP3 (Figure 2C). In the PR isolate

334 cohort, dams PR1 and 2 had detectable ZIKV IgG in sera on day 21 post infection and

335 day 32 post infection in dam PR 3 (Figure 2D).

336

337

338

339

340

341

342

343 infected with the French Polynesian ZIKV isolate (FP1) but not in dams FP2 or FP3. In

344 FP1, the ZIKV IF pattern was localized to the epithelial layer in both the endocervical

345 (upper cervix) and ectocervical (lower cervix, exterior os) regions. In the simple

346 columnar epithelium characteristic of the endocervix, the strongest IF resided near the

347 basil lamina separating the epithelium and stromal layers with diffuse IF observed in the

348 epithelial layer (Figure 3A). In the ectocervix, the stratified squamous epithelium

349 exhibited ZIKV IF in cells throughout the epithelium from the surface to the basal lamina

350 cell layer. No ZIKV IF was noted in this dam in the cervical stroma. ZIKV IF was

351 observed in the cervix of $3 / 3$ dams infected with the Puerto Rican ZIKV isolate (Figure 
352 3). In these dams, ZIKV IF was observed in the epithelial layer of both the endo- and

353 ectocervix with a more intense IF compared to the dam infected with the French

354 Polynesian isolate. In addition, occasional cells exhibited ZIKV IF in the cervical stroma,

355 potentially representing either isolated stromal cells or invading immune cells such as

356 macrophages or neutrophils. In addition, an occasional cervical gland was observed to

357 exhibit ZIKV IF (Figure 3).

358 In the cervix of the French Polynesian and Puerto Rican ZIKV isolate infected

359 dams that exhibited cervical ZIKV IF, macrophages were frequently observed in the

360 stromal layer juxtaposed to the epithelial layer (Figure 4). Puerto Rican isolate infected

361 dams (PR1, 2) exhibited a greater infiltration of macrophages into the stroma compared

362 to FP1 with macrophages being observed both adjacent to the epithelial layer as well as

363 deeper in the stromal layer (Figure 4C). In the French Polynesian isolate infected dams

364 that did not exhibit cervical ZIKV IF, only occasional macrophages were observed in the

365 stroma (Figure 4D).

367 Uterus

368 No Zika virus (pan flavivirus) IF was observed in the myometrium of any dam infected

369 with either French Polynesian or Puerto Rican ZIKV isolate (Figure 7). Occasional

370 clusters of ZIKV IF positive cells were observed in the endometrium of the two dams

371 infected with the Puerto Rican isolate that were ZIKV RNA positive in the uterus, but not

372 in the dams infected with the French Polynesian isolate or the one dam infected with the

373 Puerto Rican isolate that did not have detectable ZIKV RNA in the uterus. We did not

374 detect macrophages in any of the uterine sections examined from any animal.

375

376 Placenta and fetal membranes 
377 The dams infected with the French Polynesian ZIKV isolate were negative for ZIKV IF in

378 the placenta and fetal membranes. ZIKV IF (pan flavivirus) in the placentas of Dams

379 PR1 and PR2 (both positive for placental ZIKV RNA) demonstrated the presence of

380 ZIKV, localized primarily in the syncytial layer with regions exhibiting greater intensity

381 (Figure 5). In these two dams, we observed ZIKV IF in the amnion epithelium (PR1) and

382 in both the amnion and chorion/decidua of the fetal membranes. Of note, the fetal

383 membranes examined in this study were adjacent to the utero-placental interface and

384 not the more distal membranes. We did not observe macrophage IF in these sections

385 (Figure 6).

\section{DISCUSSION}

In the present study, we describe the ZIKV infection of six timed-pregnant olive

392 baboon semen containing $1 \times 10^{6}$ pfu of either the FP or the PR isolates of ZIKV. We

393 chose the FP isolate based on our prior study where we demonstrated vertical transfer

394 following subcutaneous inoculation with the FP isolate that resulted in both fetal demise

395 as well pronounced fetal CNS pathology (25). A retrospective study of the ZIKV

396 epidemic in French Polynesia (circa 2013) noted that this was the first instance

397 associating ZIKV to microcephaly and congenital ZIKA syndrome (CZS) $(21,26)$. It was

398 later reported that the FP isolate differs from the ancestral Asian ZIKV lineage from

399 which it was derived, with a mutation in the prM protein (S139N), which has been stably

400 maintained throughout the virus's dissemination throughout the Americas (Fig 8). This

401 mutation is associated with enhanced infectivity in human neural progenitor cells (NPCs)

402 and yielded a more significant microcephaly in mice (27). We selected the PR isolate to

403 compare to the FP isolate to examine for increased rates of vertical transfer, since it 
404 harbors the $\mathrm{S} 139 \mathrm{~N}$ mutation and has also acquired several additional point mutations

405 resulting in amino acid substitutions, some being common with the Brazilian isolate(s)

406 (28). Similar to the increased incidence of CZS noted in the Brazilian ZIKV epidemic

407 (compared to the French Polynesian estimates), a recent study by CDC reported that

408 one in seven children born from women with confirmed or possible ZIKV infection during

409 gestation in Puerto Rico had a birth defect or neurodevelopmental abnormality

410 suggesting possible mutations in this ZIKV isolate may contribute to the increased viral

411 replication and neurovirulence compared to the FP strain (29).

In the current study, ZIKV inoculations were repeated at seven-day intervals until

414 viremia was evident via qPCR or through three inoculations if no viremia was observed

415 (one PR infected dam). We chose multiple inoculations to mimic probably repeat

416 intercourse in human couples. Viremia was achieved in all dams except one of the three

417 baboons inoculated with the PR isolate noted between days 4 and 14 post infection (Fig

418 1). In those animals inoculated with the FP isolate, resolution was noted by day 14 post

419 infection, while in dams inoculated with the PR isolate, one dam had resolution by day

42011 post infection with reemergence at day 14 post infection with resolution noted again

421 at day 21 post infection (PR 2). The other PR dam (PR 1) had resolution by day 21 post

422 infection and reemergence at day 28 post infection. The course of viremia in response to

423 vaginal delivery of ZIKV infected semen differed from that described in our previous

424 study in mid-gestation pregnant baboons subcutaneously inoculated with FP isolate of

425 ZIKV where viremia was resolved by $14 \mathrm{dpi}(25)$. Therefore, the route of infection with

426 ZIKV seems to affect the length of viremia and may even affect resolution and re-

427 emergence of the virus. We can speculate that the re-emergence of the virus could be

428 attributed to the virus from several reservoirs where ZIKV has been found to persist,

429 including the gastrointestinal tract, the cerebrospinal fluid, and the lymph nodes. These 
430 tissues have been shown to persistently harbor ZIKV despite a robust immune response

$431(21,25,30-32)$. We found persistence of ZIKV RNA in both reproductive tissues as well

432 as lymph nodes at the end of the study, serving as possible reservoirs for viral re-entry in

433 the present study. While the lymph nodes were found to contain ZIKV RNA at the

434 termination of the study in both FP and PR isolate inoculated dams, only the PR dams

435 exhibited re-emergence of viremia (Table 3). This could be either strain related from an

436 increased virulence of the PR isolate or from the reproductive tissues since only the PR

437 isolate inoculated dams exhibited vaginal or uterine ZIKV RNA at the study termination.

438 Unlike the paper by Müller et al (17) describing the inhibition of ZIKV infection of cells

439 extracted from human anogenital tract and various human reproductive tissue explants

440 by human semen treatment, we detected ZIKV infection in bodily fluids and tissues of

441 dams infected vaginally by semen samples from ZIKA seronegative male baboons

442 mixed with either FP or PR ZIKV isolate. Therefore, semen did not prevent ZIKV

443 infection in baboons inoculated vaginally with ZIKV. Several studies in mice have also

444 shown sexual transmission of ZIKV through mating of ZIKV infected male mice with

445 ZIKV naïve female mice and in utero transmission in pregnant mice due to sexual

446 transmission $(20,33,34)$.

447 Studies have shown extended viremia in pregnant macaques following

448 subcutaneous inoculation where viremia is characteristically prolonged for several weeks

449 to months (35-37). It has been proposed that the prolonged or re-emergence of viremia

450 in macaques could be from tissues harboring ZIKV including placenta (38). It is also

451 noteworthy for the latter that only the PR isolate inoculated baboon dams exhibited ZIKV

452 RNA in the placenta. In humans, viremia lasting up to 53 days has been reported (24),

453 but more typically it is short in duration, lasting three to seven days (39). We cannot,

454 however, discount the possibility that we could have seen extended viremia in the one 
455 PR dam (PR1) post $28 \mathrm{dpi}$ and/or re-emergence on a different time point in any of the

456 dams had we extended the study for a longer duration rather than termination at 28dpi.

457 In addition to the differences in viremia in terms of duration, resolution and re-

458 emergence between the FP and the PR ZIKV isolates, it is of potential interest that the

459 two dams inoculated with the PR isolate had viremia levels one to two orders of

460 magnitude compared to the FP isolate inoculated dams (Fig 1). Whether this can be

461 attributed to a greater capacity for infectivity by the PR isolate or simply variability in a

462 small cohort study remains to be determined.

Despite viremia being observed in five of six dams, vaginal infection with FP and

464 PR isolate presented with slight to negligible rash on the abdomen and in the axillary

465 and inguinal regions with little or no conjunctivitis. Only one dam inoculated with FP

466 isolate (FP1) presented with moderate rash and mild conjunctivitis. Dams infected with

467 PR isolate presented with slight to negligible rash on the abdomen and bilateral axillary

468 and inguinal regions with no conjunctivitis. One PR dam (PR3) presented with slight to

469 mild rash on the lower abdomen, axillary and inguinal regions and slight to negligible

470 conjunctivitis. None of the dams exhibited any other signs of decreased appetite, water

471 intake, signs of fever or arthralgia. This lack of presentation of clinical signs after vaginal

472 inoculation of ZIKV differed from the moderate to severe clinical signs we observed in all

473 baboons (primarily rash and conjunctivitis) that we previously infected subcutaneously

474 with the FP isolate in prior studies of mid-gestation pregnant baboons (24), as well as

475 non-pregnant female baboons (21), and male baboons $(15,21)$. The difference in

476 presentation of clinical signs is likely due to the different routes of ZIKV inoculation

477 (subcutaneous vs vaginal) and is of significant clinical importance since, unlike,

478 subcutaneous infection, ZIKV infection via sexual intercourse may be more 
479 asymptomatic than usual and therefore, evade preventive measures which could 480 preclude diagnosis, in particular in pregnancy.

4824 through 28 dpi while resolving by 21 dpi in dams FP2, 3. In the PR infected cohort, 483 ZIKV RNA was detected in the CVW of dam PR1 from 4dpi through 28 dpi whereas in 484 dam PR2, ZIKV RNA was not detected until 21dpi and resolved by 28dpi (Fig 1E,F). 485 The delayed detection of ZIKV RNA in the wash of PR3 may reflect that this dam was 486 not infected by vaginal semen inoculation until the $3^{\text {rd }}$ attempt (day 14 post-initial 487 inoculation) and also may help explain the lack of viremia observed in this dam. The 488 longer presence of vRNA in CVW is distinct from blood and saliva and could contribute 489 to the re-emergence of viremia in dam PR1 (14 days non viremic between last viremic 490 time point and re-emergence) and dam PR2 (7 days non-viremic between last viremia 491 time point and re-emergence). However, it is noteworthy that the FP dams did not show 492 re-emergence of viremia even though one (FP1) had prolonged virus in the CVW (28 493 dpi). This may be possibly related to differences in infectivity of the two isolates.

494 In addition to the fluid compartments, we found ZIKV RNA persisting in the lymph 495 nodes of all animals from both FP and PR isolate cohorts. In rhesus macaques, ZIKV

496 RNA has been detected in the lymph nodes for 5 to 6 weeks post infection (30).

497 Presence of ZIKV in the lymph nodes is one possible route of disseminating the virus 498 from vagina to the cervix and uterus. The lymphatic system may serve as a reservoir for 499 ZIKV persistence as well as sites of re-emergence of the virus through viral shedding 500 from the local lymphatic tissue, possibly on an intermittent basis, by supplying virus to 501 glandular tissue (via local lymphatic vascular beds) leading to secretion into the bodily 502 fluids. However, at this time, we do not know if the ZIKV found in the saliva, blood, lymph 
503 nodes, reproductive tissues or cervico-vaginal washings at the termination of the study

504 was infectious virus.

$505 \quad$ ZIKV RNA was not detected in any reproductive tissues of the dams infected with

506 the FP isolate. However, cervical tissue of dam FP1 was found positive for ZIKV IF

507 staining. The CVW samples of the other two FP dams were ZIKV positive only on days

5084,11 and 14 and were not ZIKV positive by qPCR or IF staining. The CVW from dam

509 FP1 was positive for ZIKV RNA from day 4 through 28 post infection. It is possible that

510 our inability to detect ZIKV RNA in the cervix in this dam (and the others) is related to its

511 restriction to the epithelial layer and not stroma. In the cervix, the majority of the tissue

512 is stromal and our tissue sampling for RNA analysis excluded epithelium. Alternatively,

513 since the epithelium represents such a small contribution to the total RNA from cervix (vs

514 stroma) that ZIKV RNA was below the exclusion limit for detection ( $1 \times 10^{2}$ copies) that we

515 set. In the PR isolate cohort, the cervix of all three dams were positive for ZIKV IF. Dams

516 PR1 and 3 had detectable ZIKV RNA in the vaginal tissue. It is noteworthy that the

517 vagina, which is continuous with the cervix, differs from the cervix in that it has a large

518 stratified squamous epithelium that may help in harboring the virus. Dams PR1 and 2

519 were positive for ZIKV (RNA and protein) in the uterus as well, and positive ZIKV IF

520 staining in the fetal membranes and placenta of the same two PR infected dams

521 suggests possible spread of ZIKV to the fetus per se had the study been for a longer

522 duration. Dams PR1 and 2 had prolonged detection of ZIKV RNA in CVW samples

523 possibly explaining positive ZIKV IF in the cervical tissue. Although CVW samples of

524 dam PR 3 were negative for ZIKV RNA, cervical tissue was positive for ZIKV IF staining

525 and ZIKV RNA was detected in the vaginal tissue. It is possible that ZIKV in this animal

526 was restricted to select tissues such as the cervix, vagina and lymph nodes and

527 remained tissue localized rather than replicate and spread as suggested by the lack of

528 viremia after three inoculations and weak IgM and IgG response to ZIKV. The presence 
529 of ZIKV virus in different reproductive tissues after vaginal transfer of the virus suggests

530 that the reproductive organs in baboons may harbor ZIKV during the acute phase of

531 ZIKV infection through sexual transmission.

532 Recruitment of macrophages into the cervical stroma has been described during

533 late gestation and proposed as playing an essential role in the remodeling of cervical

534 stroma tissue, essential for cervical ripening in preparation for parturition (40). The cervix

535 is referred to as the "gatekeeper" of pregnancy and as such, a premature recruitment of

536 immune cells into the cervix in response to lower reproductive tract infection has been

537 proposed to induce premature loss of cervical integrity playing a key role in pre-term

538 birth. Cervical macrophage infiltration is well reported in pre-term and term cervix in

539 human and animal models (41). Abortion and preterm birth are well described in

540 response to ZIKV in humans and NHPs including baboons, as we have described (25).

541 Macrophages can induce cervical connective tissue remodeling via their expression of

542 matrix metalloproteinases (MMPs), and various other factors that help in the breakdown

543 of collagen and junction proteins resulting in the loss of cervical epithelial integrity

544 required for cervical ripening (42). In relation to this, we observed ZIKV IF in the cervix of

545 one FP isolate inoculated dam and all three PR isolate inoculated dams (Fig 3). For

546 both isolates, the ZIKV IF was localized to the epithelial layer of the cervix in both endo-

547 and ectocervical regions. The strongest ZIKV IF intensity was localized at the basal

548 aspect of the epithelial cells at the junction with the stromal layer, which consists

549 primarily of fibroblasts and smooth muscle cells. Macrophage IF was observed in both

550 the FP isolate dam exhibiting ZIKV IF in cervical epithelium as well as all three ZIKV IF

551 positive PR isolate dams in the epithelium (Fig 4). Relative to this, macrophages were

552 routinely observed in the cervix of only the FP isolate dam with cervical ZIKV IF and the

553 three PR isolate dams. In the FP dam, macrophages were observed in the stromal

554 tissue immediately adjacent to the epithelium, indicative of recruitment (of monocytes) in 
555 response to the virus itself or from a local inflammatory reaction in response to ZIKV

556 infection of epithelial cells. In the PR infected dams, macrophages were also noted

557 adjacent to the epithelial layer as well as deeper in the stromal tissue, possibly indicating

558 potential breakdown of the epithelial-stromal barrier and entry of virus into the stromal

559 tissue. In contrast, FP dams with no ZIKV IF staining in cervix had only occasional

560 macrophage staining in the stromal layer, typically scattered throughout the stroma. It is

561 possible that the recruitment of macrophages due to ZIKV infection of the cervix through

562 vaginal route at mid-gestation may induce breakdown of epithelial cell barrier and

563 integrity similar to during cervical ripening at term. This breakdown could potentially lead

564 to viral access to the adjacent reproductive tissues such as the uterus and placenta but

565 more importantly, fetal membranes which lie at the top of the cervical canal thus

566 amniotic sac and fluid and ultimately, the fetal compartment, thus exposing the fetus to

567 Zika viral infection.

568 Vertical transfer of ZIKV in macaques appear to be very efficient, described to

569 occur at near $100 \%$ following infection using various isolates of ZIKV including FP (37,

$57038), \operatorname{PR}(31,35,43), \operatorname{BR}(32,44)$ and $\operatorname{RIO}(45,46)$ isolates. While we observed no

571 placental infection in the FP isolate inoculated pregnancies, vertical transfer to the

572 placenta was observed (both RNA and IF) in two of the three animals infected with the

573 PR isolate (Fig 5). In these two animals (dams PR1, 2), ZIKV RNA was detected in

574 multiple cotyledons indicating widespread targeting of the placenta. Similar to our prior

575 study infecting dams with the FP isolate (25), ZIKV IF was noted in the trophoblast cells.

576 Since the one PR isolate inoculated dam without placental ZIKV targeting also was the

577 dam with no noted viremia and latent detection in the CVW, this animal may have been

578 infected by a later inoculation while it is clear that dams PR1 and 2 were infected at the

579 first inoculation based on viremia, exhibited ZIKV RNA in the uterus and had prolonged 
ZIKV in the CVW. These dams also had notable ZIKV IF in the fetal membranes

581 indicating that breakthrough of the virus through the placental barrier may have occurred

582 since the membranes used for IF were at the uterus-placental interface or possibly via

583 loss of cervical integrity leading to the opening of cervical canal and access to the

584 membranes. While we found ZIKV RNA and IF in the placenta of two PR inoculated

585 dams, there was no evidence of vertical transfer of the virus to any of the fetal

586 compartments in any of the animals inoculated. The route of ZIKV infection,

587 subcutaneous vs. vaginal may affect the rate and frequency of vertical transfer to the

588 fetus per se. Considering the prolonged presence of virus in the CVW, the presence of

589 ZIKV RNA and IF in placental trophoblasts and fetal membranes, and the unanticipated

590 re-emergence of viremia (prolonged viremia) in these two PR inoculated dams, we

591 predicted that vertical transfer would have occurred in these baboons at a later period,

592 Further studies are needed to follow intravaginally ZIKV infected pregnant baboons for

593 longer periods post-infection to better understand the fetal outcome of delayed viremia

594 and potential re-emergence from immune privileged sites harboring ZIKV such as the

595 lymph nodes.

With regard to the adaptive immune response to ZIKV infection, all six of the

597 baboons inoculated with ZIKV developed ZIKV-specific IgM and IgG responses (Fig 2).

598 IgM production following ZIKV infection was noted in all animals at variable times which

599 indicated that the maternal immune system had access to the virus despite the lack of

600 viremia in one of the three animals inoculated with the PR isolate. While, IgG titers were

601 detected in all the dams $21 \mathrm{dpi}$, this was either too slow or inadequate to prevent spread

602 of the virus to various reproductive tissues. It is noteworthy that the $\lg M$ and $\lg G$

603 response was also delayed in the dam inoculated with the FP isolate that displayed

604 delayed viremia (11 dpi; FP3), being observed initially at 21 days (IgM) and 35 dpi (IgG). 
605 Also, noteworthy, the one PR isolate infected dam that did not exhibit viremia had a

606 similar weak $\operatorname{lgM}$ response (21 dpi) as well as $\operatorname{lgG}(35 \mathrm{dpi})$, with the immune cells likely

607 being exposed to ZIKV via lymph nodes. It is unclear if these dams would have

608 developed a robust neutralizing IgG response if examined at later times post-inoculation.

609 As such, we can only speculate that some instances of sexual transmission of ZIKV may

610 not result in a robust, neutralizing adaptive immune response.

611 While we acknowledge the small animal numbers in our study comparing PR and

612 FP ZIKV isolates, there are clear indications that the PR isolate was more virulent in

613 comparison to the FP isolate in terms of level of viremia, re-emergence of viremia,

614 targeting of reproductive tissues and importantly, infection of the placenta and high

615 potential for vertical transfer to the fetus per se. Few studies to date have focused on

616 the effect of accumulated mutations in the virus acquired in the Americas compared to

617 either the ancestral Asian isolate or the French Polynesian isolate that acquired the

618 noted S139N substitution in the prM protein. Brazilian isolates, most notably the Rio

619 isolate (RIO-U1/2016) acquired additional substitutions and the PR isolate differs in

620 several other residues, some common with the Rio isolate (Fig 8). How these mutations

621 may have increased virulence remains equivocal. However, viral modulation of the host

622 immune response is a necessary factor for infection of the host and propagation of the

623 progeny virus. All viruses must encode for at least one protein in their genome to

624 modulate the host response to establish a successful infection. In the case of

625 flaviviruses, many of the nonstructural proteins interact with cellular signaling cascades

626 to instate a favorable environment for viral replication through resistance of host defense

627 mechanisms (47). For flaviviruses, host response modulation is focused on the

628 interferon response, and the level of modulation is directly proportional to pathogenicity

629 as well as host species specificity (48). The increased virulence noted here for the

630 Puerto Rican Strain (PRVABC59) compared to the isolate from French Polynesia 
$631(\mathrm{H} / \mathrm{FP} / 2013)$ could be interpreted as a difference in modulation of host response.

632 Alignment of the complete polyprotein from H/PF/2013, Brazilian RIO isolate, and

633 PRVABC59, revealed specific amino acid changes in non-structural proteins NS1

634 (Lys1059 $\rightarrow$ Glu) and NS5 (Ala2611 $\rightarrow$ Val) of PRVABC59 that were not present in either

$635 \mathrm{H} / \mathrm{PF} / 2013$ or the RIO isolate (Fig 8). NS1 and NS5 play important roles in flavivirus

636 replication, but have also been implicated in modulation of the host response through

637 interaction with a variety of host proteins (49-51). Targeting of the interferon response by

638 NS1 and NS5 has been documented for multiple flaviviruses including ZIKV (52-54) and

639 the inhibition of IFN $\beta$ by NS1 can be mapped to a specific amino acid residue (49).

640 Considering this, along with the multiple and complex ways flavivirus non-structural

641 proteins manipulate the host response, the single amino acid changes identified in NS1

642 and NS5 for PRVABC59 could account for the increase in virulence for this specific

643 isolate through altered interactions with host cellular proteins. However, further

644 investigation is necessary to confirm this hypothesis. Domain III of the flavivirus

645 envelope protein participates in receptor recognition and contains linear epitopes

646 recognized by neutralizing antibodies (55). Interestingly, the single amino acid change in

647 the envelope protein of PRVABC59 resides in domain III (Val620 $\rightarrow$ Leu, Fig 8). This

648 could possibly be due to the selective pressure of neutralizing antibodies as the virus

649 moved from French Polynesia through Brazil into Puerto Rico. However, the two

650 residues are highly similar hydrophobic amino acids, and it is highly likely the change is

651 of no consequence to viral pathogenicity.

652 In conclusion, this study further clarified the transmission of ZIKV following

653 intravaginal inoculation during pregnancy in a novel non-human primate model. This

654 important translational model not only more closely recapitulates the course of observed

655 infection patterns in humans, it also offers a novel comparator of the infectivity of two

656 contemporary ZIKV isolates. The FP isolate, which was more rarely associated with 
657 vertical transmission than the PR isolate, appears to follow the same pattern within this

658 study, which is logical given that ZIKV has continued to mutate during its passage from

659 French Polynesia to the Americas. Future studies, some of which our lab is currently

660 undertaking, can focus on the long-term outcomes of ZIKV viral infection following

661 vaginal inoculation during early and mid-gestation in pregnancies that are allowed to

662 continue gestating until term. This would be of value as sexual transmission of

663 flaviviruses such as ZIKV may allow viral persistence or transmission to geographic

664 locales when mosquito transmission is less likely, such as in the winter season. It is also

665 a potential mechanism by which ZIKV infection can be spread to a population naïve to

666 the ZIKV infection. Additionally, the course of ZIKV infection following sexual

667 transmission and its consequences to the fetus appear different from subcutaneous

668 ZIKV infection and what that means for the developing fetus and vaccine development is

669 yet to be elucidated. This knowledge may help develop guidelines, preventative

670 measures and therapeutics to protect against sexual transmission of ZIKV.

\section{ACKNOWLEDGEMENTS}

673 Oklahoma Baboon Research Resource; Helen Lazear, University of North Carolina

674 Chapel Hill, Mukesh Kumar, Georgia State University, Atlanta, GA, for providing ZIKV

675 stocks; Oklahoma medical research foundation (OMRF) for tissue processing and

676 immunostaining and James Tomasek, Vice President for Research, University of

677 Oklahoma Health Sciences Center. 
684 1. Frieden TR, Schuchat A, Petersen LR. 2016. Zika Virus 6 Months Later. Jama Espinoza J, Seferovic MD, Lee W, Hotez P, Mastrobattista J, Clark SL, Belfort MA, Aagaard KM. 2017. Testing for Zika virus infection in pregnancy: key concepts to deal with an emerging epidemic. Am J Obstet Gynecol 216:209-225.

3. Rasmussen SA, Jamieson DJ, Honein MA, Petersen LR. 2016. Zika Virus and Birth Defects--Reviewing the Evidence for Causality. N Engl J Med 374:1981-1987.

4. Allard A, Althouse BM, Hebert-Dufresne L, Scarpino SV. 2017. The risk of sustained sexual transmission of Zika is underestimated. PLoS Pathog 13:e1006633.

5. Coelho FC, Durovni B, Saraceni V, Lemos C, Codeco CT, Camargo S, de Carvalho LM, Bastos L, Arduini D, Villela DA, Armstrong M. 2016. Higher incidence of Zika in adult women than adult men in Rio de Janeiro suggests a significant contribution of sexual transmission from men to women. Int J Infect Dis 51:128-132.

6. Grischott F, Puhan M, Hatz C, Schlagenhauf P. 2016. Non-vector-borne transmission of Zika virus: A systematic review. Travel Med Infect Dis 14:313-330.

7. Davidson A, Slavinski S, Komoto K, Rakeman J, Weiss D. 2016. Suspected Female-to-Male Sexual Transmission of Zika Virus - New York City, 2016. MMWR Morb Mortal Wkly Rep 65:716-717.

8. Arsuaga M, Bujalance SG, Diaz-Menendez M, Vazquez A, Arribas JR. 2016. Probable sexual transmission of Zika virus from a vasectomised man. Lancet Infect Dis 16:1107.

9. Coelho AVC, Crovella S. 2017. Microcephaly Prevalence in Infants Born to Zika Virus-Infected Women: A Systematic Review and Meta-Analysis. Int J Mol Sci 18.

10. Foy BD, Kobylinski KC, Chilson Foy JL, Blitvich BJ, Travassos da Rosa A, Haddow AD, Lanciotti RS, Tesh RB. 2011. Probable non-vector-borne transmission of Zika virus, Colorado, USA. Emerg Infect Dis 17:880-882.

11. Hall V, Walker WL, Lindsey NP, Lehman JA, Kolsin J, Landry K, Rabe IB, Hills SL, Fischer M, Staples JE, Gould CV, Martin SW. 2018. Update: Noncongenital Zika Virus Disease Cases - 50 U.S. States and the District of Columbia, 2016. MMWR Morb Mortal Wkly Rep 67:265-269.

12. Oliveira DB, Almeida FJ, Durigon EL, Mendes EA, Braconi CT, Marchetti I, Andreata-Santos R, Cunha MP, Alves RP, Pereira LR, Melo SR, Neto DF, Mesquita FS, Araujo DB, Favoretto SR, Safadi MA, Ferreira LC, Zanotto PM, Botosso VF, Berezin EN. 2016. Prolonged Shedding of Zika Virus Associated with Congenital Infection. N Engl J Med 375:1202-1204.

13. Desclaux A, de Lamballerie X, Leparc-Goffart I, Vilain-Parce A, Coatleven F, Fleury H, Malvy D. 2018. Probable Sexually Transmitted Zika Virus Infection in a Pregnant Woman. N Engl J Med 378:1458-1460.

14. Nicastri E, Castilletti C, Liuzzi G, Iannetta M, Capobianchi MR, Ippolito G. 2016. Persistent detection of Zika virus RNA in semen for six months after symptom onset in a traveller returning from Haiti to Italy, February 2016. Euro Surveill 21.

15. Peregrine J, Gurung S, Lindgren MC, Husain S, Zavy MT, Myers DA, Papin JF. 2019. Zika virus infection, reproductive organ targeting, and semen transmission in the male olive baboon. J Virol doi:10.1128/JVI.01434-19.

730

16. Yockey LJ, Varela L, Rakib T, Khoury-Hanold W, Fink SL, Stutz B, Szigeti-Buck K, Van den Pol A, Lindenbach BD, Horvath TL, Iwasaki A. 2016. Vaginal Exposure 
to Zika Virus during Pregnancy Leads to Fetal Brain Infection. Cell 166:1247-1256 e1244.

17. Muller JA, Harms M, Kruger F, Gross R, Joas S, Hayn M, Dietz AN, Lippold S, von Einem J, Schubert A, Michel M, Mayer B, Cortese M, Jang KS, Sandi-Monroy N, Deniz M, Ebner F, Vapalahti O, Otto M, Bartenschlager R, Herbeuval JP, Schmidt-Chanasit J, Roan NR, Munch J. 2018. Semen inhibits Zika virus infection of cells and tissues from the anogenital region. Nat Commun 9:2207.

18. Russell K, Hills SL, Oster AM, Porse CC, Danyluk G, Cone M, Brooks R, Scotland S, Schiffman E, Fredette C, White JL, Ellingson K, Hubbard A, Cohn A, Fischer M, Mead P, Powers AM, Brooks JT. 2017. Male-to-Female Sexual Transmission of Zika Virus-United States, January-April 2016. Clin Infect Dis 64:211-213.

19. Deckard DT, Chung WM, Brooks JT, Smith JC, Woldai S, Hennessey M, Kwit N, Mead P. 2016. Male-to-Male Sexual Transmission of Zika Virus--Texas, January 2016. MMWR Morb Mortal Wkly Rep 65:372-374.

20. Duggal NK, McDonald EM, Ritter JM, Brault AC. 2018. Sexual transmission of Zika virus enhances in utero transmission in a mouse model. Sci Rep 8:4510.

21. Gurung S, Preno AN, Dubaut JP, Nadeau H, Hyatt K, Reuter N, Nehete B, Wolf RF, Nehete P, Dittmer DP, Myers DA, Papin JF. 2018. Translational Model of Zika Virus Disease in Baboons. J Virol doi:10.1128/jvi.00186-18.

22. Styer LM, Kent KA, Albright RG, Bennett CJ, Kramer LD, Bernard KA. 2007. Mosquitoes inoculate high doses of West Nile virus as they probe and feed on live hosts. PLoS Pathog 3:1262-1270.

23. Dudley DM, Newman CM, Lalli J, Stewart LM, Koenig MR, Weiler AM, Semler MR, Barry GL, Zarbock KR, Mohns MS, Breitbach ME, Schultz-Darken N, Peterson E, Newton W, Mohr EL, Capuano Iii S, Osorio JE, O'Connor SL, O'Connor DH, Friedrich TC, Aliota MT. 2017. Infection via mosquito bite alters Zika virus tissue tropism and replication kinetics in rhesus macaques. Nat Commun 8:2096.

24. Lanciotti RS, Kosoy OL, Laven JJ, Velez JO, Lambert AJ, Johnson AJ, Stanfield SM, Duffy MR. 2008. Genetic and serologic properties of Zika virus associated with an epidemic, Yap State, Micronesia, 2007. Emerg Infect Dis 14:1232-1239.

25. Gurung S, Reuter N, Preno A, Dubaut J, Nadeau H, Hyatt K, Singleton K, Martin A, Parks WT, Papin JF, Myers DA. 2019. Zika virus infection at mid-gestation results in fetal cerebral cortical injury and fetal death in the olive baboon. PLoS Pathog 15:e1007507.

26. Cauchemez S, Besnard M, Bompard P, Dub T, Guillemette-Artur P, EyrolleGuignot D, Salje H, Van Kerkhove MD, Abadie V, Garel C, Fontanet A, Mallet HP. 2016. Association between Zika virus and microcephaly in French Polynesia, 201315: a retrospective study. Lancet 387:2125-2132.

27. Yuan L, Huang XY, Liu ZY, Zhang F, Zhu XL, Yu JY, Ji X, Xu YP, Li G, Li C, Wang HJ, Deng YQ, Wu M, Cheng ML, Ye Q, Xie DY, Li XF, Wang X, Shi W, Hu B, Shi PY, Xu Z, Qin CF. 2017. A single mutation in the prM protein of Zika virus contributes to fetal microcephaly. Science 358:933-936.

28. Agrelli A, de Moura RR, Crovella S, Brandao LAC. 2019. Mutational landscape of Zika virus strains worldwide and its structural impact on proteins. Gene 708:57-62.

29. Rice ME, Galang RR, Roth NM, Ellington SR, Moore CA, Valencia-Prado M, Ellis EM, Tufa AJ, Taulung LA, Alfred JM, Perez-Padilla J, Delgado-Lopez CA, Zaki SR, Reagan-Steiner S, Bhatnagar J, Nahabedian JF, 3rd, Reynolds MR, YearginAllsopp M, Viens LJ, Olson SM, Jones AM, Baez-Santiago MA, Oppong-Twene P, VanMaldeghem K, Simon EL, Moore JT, Polen KD, Hillman B, Ropeti R, Nieves- 
Ferrer L, Marcano-Huertas M, Masao CA, Anzures EJ, Hansen RL, Jr., PerezGonzalez SI, Espinet-Crespo CP, Luciano-Roman M, Shapiro-Mendoza CK, Gilboa SM, Honein MA. 2018. Vital Signs: Zika-Associated Birth Defects and Neurodevelopmental Abnormalities Possibly Associated with Congenital Zika Virus Infection - U.S. Territories and Freely Associated States, 2018. MMWR Morb Mortal Wkly Rep 67:858-867.

30. Aid M, Abbink P, Larocca RA, Boyd M, Nityanandam R, Nanayakkara O, Martinot AJ, Moseley ET, Blass E, Borducchi EN, Chandrashekar A, Brinkman AL, Molloy K, Jetton D, Tartaglia LJ, Liu J, Best K, Perelson AS, De La Barrera RA, Lewis MG, Barouch DH. 2017. Zika Virus Persistence in the Central Nervous System and Lymph Nodes of Rhesus Monkeys. Cell 169:610-620.e614.

31. Hirsch AJ, Smith JL, Haese NN, Broeckel RM, Parkins CJ, Kreklywich C, DeFilippis VR, Denton M, Smith PP, Messer WB, Colgin LM, Ducore RM, Grigsby PL, Hennebold JD, Swanson T, Legasse AW, Axthelm MK, MacAllister R, Wiley CA, Nelson JA, Streblow DN. 2017. Zika Virus infection of rhesus macaques leads to viral persistence in multiple tissues. PLoS Pathog 13:e1006219.

32. Coffey LL, Pesavento PA, Keesler RI, Singapuri A, Watanabe J, Watanabe R, Yee J, Bliss-Moreau E, Cruzen C, Christe KL, Reader JR, von Morgenland W, Gibbons AM, Allen AM, Linnen J, Gao K, Delwart E, Simmons G, Stone M, Lanteri M, Bakkour S, Busch M, Morrison J, Van Rompay KK. 2017. Zika Virus Tissue and Blood Compartmentalization in Acute Infection of Rhesus Macaques. PLoS One 12:e0171148.

33. Clancy CS, Van Wettere AJ, Morrey JD, Julander JG. 2018. Coitus-Free Sexual Transmission of Zika Virus in a Mouse Model. Sci Rep 8:15379.

34. Uraki R, Jurado KA, Hwang J, Szigeti-Buck K, Horvath TL, Iwasaki A, Fikrig E. 2017. Fetal Growth Restriction Caused by Sexual Transmission of Zika Virus in Mice. J Infect Dis 215:1720-1724.

35. Hirsch AJ, Roberts VHJ, Grigsby PL, Haese N, Schabel MC, Wang X, Lo J0, Liu Z, Kroenke CD, Smith JL, Kelleher M, Broeckel R, Kreklywich CN, Parkins CJ, Denton M, Smith P, DeFilippis V, Messer W, Nelson JA, Hennebold JD, Grafe M, Colgin L, Lewis A, Ducore R, Swanson T, Legasse AW, Axthelm MK, MacAllister R, Moses AV, Morgan TK, Frias AE, Streblow DN. 2018. Zika virus infection in pregnant rhesus macaques causes placental dysfunction and immunopathology. Nat Commun 9:263.

36. Carroll T, Lo M, Lanteri M, Dutra J, Zarbock K, Silveira P, Rourke T, Ma ZM, Fritts L, O'Connor S, Busch M, Miller CJ. 2017. Zika virus preferentially replicates in the female reproductive tract after vaginal inoculation of rhesus macaques. PLoS Pathog 13:e1006537.

37. Nguyen SM, Antony KM, Dudley DM, Kohn S, Simmons HA, Wolfe B, Salamat MS, Teixeira LBC, Wiepz GJ, Thoong TH, Aliota MT, Weiler AM, Barry GL, Weisgrau KL, Vosler LJ, Mohns MS, Breitbach ME, Stewart LM, Rasheed MN, Newman CM, Graham ME, Wieben OE, Turski PA, Johnson KM, Post J, Hayes JM, SchultzDarken N, Schotzko ML, Eudailey JA, Permar SR, Rakasz EG, Mohr EL, Capuano S, 3rd, Tarantal AF, Osorio JE, O'Connor SL, Friedrich TC, O'Connor DH, Golos TG. 2017. Highly efficient maternal-fetal Zika virus transmission in pregnant rhesus macaques. PLoS Pathog 13:e1006378.

38. Dudley DM, Aliota MT, Mohr EL, Weiler AM, Lehrer-Brey G, Weisgrau KL, Mohns MS, Breitbach ME, Rasheed MN, Newman CM, Gellerup DD, Moncla LH, Post J, Schultz-Darken N, Schotzko ML, Hayes JM, Eudailey JA, Moody MA, Permar SR, O'Connor SL, Rakasz EG, Simmons HA, Capuano S, Golos TG, Osorio 
JE, Friedrich TC, O'Connor DH. 2016. A rhesus macaque model of Asian-lineage Zika virus infection. Nat Commun 7:12204.

39. Brasil P, Pereira JP, Jr., Moreira ME, Ribeiro Nogueira RM, Damasceno L, Wakimoto M, Rabello RS, Valderramos SG, Halai UA, Salles TS, Zin AA, Horovitz D, Daltro P, Boechat M, Raja Gabaglia C, Carvalho de Sequeira P, Pilotto JH, Medialdea-Carrera R, Cotrim da Cunha D, Abreu de Carvalho LM, Pone $M$, Machado Siqueira A, Calvet GA, Rodrigues Baiao AE, Neves ES, Nassar de Carvalho PR, Hasue RH, Marschik PB, Einspieler C, Janzen C, Cherry JD, Bispo de Filippis AM, Nielsen-Saines K. 2016. Zika Virus Infection in Pregnant Women in Rio de Janeiro. N Engl J Med 375:2321-2334.

40. Yellon SM. 2017. Contributions to the dynamics of cervix remodeling prior to term and preterm birth. Biol Reprod 96:13-23.

41. Nold C, Jensen T, O'Hara K, Stone J, Yellon SM, Vella AT. 2019. Replens prevents preterm birth by decreasing type I interferon strengthening the cervical epithelial barrier. Am J Reprod Immunol doi:10.1111/aji.13192:e13192.

42. Myers DA. 2012. The recruitment and activation of leukocytes into the immune cervix: further support that cervical remodeling involves an immune and inflammatory mechanism. Biol Reprod 87:107.

43. Mohr EL, Block LN, Newman CM, Stewart LM, Koenig M, Semler M, Breitbach ME, Teixeira LBC, Zeng X, Weiler AM, Barry GL, Thoong TH, Wiepz GJ, Dudley DM, Simmons HA, Mejia A, Morgan TK, Salamat MS, Kohn S, Antony KM, Aliota MT, Mohns MS, Hayes JM, Schultz-Darken N, Schotzko ML, Peterson E, Capuano S, 3rd, Osorio JE, O'Connor SL, Friedrich TC, O'Connor DH, Golos TG. 2018. Ocular and uteroplacental pathology in a macaque pregnancy with congenital Zika virus infection. PLoS One 13:e0190617.

44. Martinot AJ, Abbink P, Afacan O, Prohl AK, Bronson R, Hecht JL, Borducchi EN, Larocca RA, Peterson RL, Rinaldi W, Ferguson M, Didier PJ, Weiss D, Lewis MG, De La Barrera RA, Yang E, Warfield SK, Barouch DH. 2018. Fetal Neuropathology in Zika Virus-Infected Pregnant Female Rhesus Monkeys. Cell 173:1111-1122 e1110.

45. Maness NJ, Schouest B, Singapuri A, Dennis M, Gilbert MH, Bohm RP, Schiro F, Aye PP, Baker K, Van Rompay KKA, Lackner AA, Bonaldo MC, Blair RV, Permar SR, Coffey LL, Panganiban AT, Magnani D. 2019. Postnatal Zika virus infection of nonhuman primate infants born to mothers infected with homologous Brazilian Zika virus. Scientific reports 9:12802-12802.

46. Magnani DM, Rogers TF, Maness NJ, Grubaugh ND, Beutler N, Bailey VK, Gonzalez-Nieto L, Gutman MJ, Pedreno-Lopez N, Kwal JM, Ricciardi MJ, Myers TA, Julander JG, Bohm RP, Gilbert MH, Schiro F, Aye PP, Blair RV, Martins MA, Falkenstein KP, Kaur A, Curry CL, Kallas EG, Desrosiers RC, GoldschmidtClermont PJ, Whitehead SS, Andersen KG, Bonaldo MC, Lackner AA, Panganiban AT, Burton DR, Watkins DI. 2018. Fetal demise and failed antibody therapy during Zika virus infection of pregnant macaques. Nat Commun 9:1624.

47. Beachboard DC, Horner SM. 2016. Innate immune evasion strategies of DNA and RNA viruses. Curr Opin Microbiol 32:113-119.

48. Ding Q, Gaska JM, Douam F, Wei L, Kim D, Balev M, Heller B, Ploss A. 2018. Species-specific disruption of STING-dependent antiviral cellular defenses by the Zika virus NS2B3 protease. Proceedings of the National Academy of Sciences of the United States of America 115:E6310-E6318.

49. Xia H, Luo H, Shan C, Muruato AE, Nunes BTD, Medeiros DBA, Zou J, Xie X, Giraldo MI, Vasconcelos PFC, Weaver SC, Wang T, Rajsbaum R, Shi PY. 2018. An 
evolutionary NS1 mutation enhances Zika virus evasion of host interferon induction.

50. Best SM. 2017. The Many Faces of the Flavivirus NS5 Protein in Antagonism of Type I Interferon Signaling. J Virol 91.

51. Zhou Y, Ray D, Zhao Y, Dong H, Ren S, Li Z, Guo Y, Bernard KA, Shi PY, Li H. 2007. Structure and function of flavivirus NS5 methyltransferase. J Virol 81:38913903.

52. Nazmi A, Dutta K, Hazra B, Basu A. 2014. Role of pattern recognition receptors in flavivirus infections. Virus Res 185:32-40.

53. Suthar MS, Aguirre S, Fernandez-Sesma A. 2013. Innate immune sensing of

54. Wu Y, Liu Q, Zhou J, Xie W, Chen C, Wang Z, Yang H, Cui J. 2017. Zika virus evades interferon-mediated antiviral response through the co-operation of multiple nonstructural proteins in vitro. Cell Discov 3:17006.

55. Zhang X, Jia R, Shen H, Wang M, Yin Z, Cheng A. 2017. Structures and Functions of the Envelope Glycoprotein in Flavivirus Infections. Viruses $\mathbf{9}$. 


\section{FIGURE LEGENDS}

917 Figure 1. ZIKV RNA in blood (viremia, A, B), saliva (C, D) or cervico-vaginal washes (E,

918 F) in mid-trimester baboons inoculated intra-vaginally with baboon semen containing

919 either the FP or PR ZIKV isolates. ZIKV RNA was prepared from specimens collected

920 from each animal at the indicated days post-infection and quantitated by one-step qRT-

921 PCR.

922 Figure 2. Serum ZIKV $\operatorname{Ig} M(A, B)$ and $\lg G(C, D)$ at the indicated days post-infection in

923 mid-trimester baboons inoculated intra-vaginal with baboon semen containing either the

924 FP or PR ZIKV isolates. The dashed lines represent the assay cutoff controls for IgM

925 and $\lg$ detection in each specific ELISA.

926 Figure 3. Pan flavivirus immunofluorescence (IF; panflavi, Red; DAPI, Blue) in the

927 cervix. In the endocervix (A, B; upper cervix) ZIKV IF (dashed white arrows) was

928 localized in the epithelium (denoted by the dashed lines) in both the endocervical region

929 (A,B; simple columnar epithelium) and the ectocervix (CD; lower cervical-vaginal region,

930 stratified squamous epithelium) in both PR and FP inoculated dams. In the FP isolate

931 inoculated dam (FP1), intense ZIKV IF was observed at the interface of the epithelial-

932 stromal junction in the endocervical region (A, B) with a broader distribution in the

933 epithelium in the ectocervical region $(C, D)$. In the PR isolate infected dams $(B, D)$ a

934 more intense ZIKV IF staining was noted in the epithelium of both the cervical regions as

935 well as in occasional cells in the stroma (white arrow, B). In one PR isolate infected dam,

936 ZIKV IF was also noted in the cervical glands ( $F$, dashed white arrows). For

937 comparison, a dam infected with the FP isolate $(E)$ that did not exhibit ZIKV IF in either

938 cervical region is shown. Small arrowheads denote auto-fluorescing red blood cells. 
939 Figure 4. Immunofluorescent staining in the cervix for macrophages (Red; DAPI: Blue).

940 In both FP isolate and PR isolate infected dams, abundant macrophages were observed,

941 in the FP isolate infected dam that exhibited ZIKV IF (A, FP1), macrophages (dashed

942 arrows) were primarily localized at or near the epithelial-stromal interface. In the PR

943 isolate dams that were ZIKV IF positive, macrophages were localized at the both the

944 epithelial-stromal interface region (B) as well as deeper in the stomal tissue (C). In

945 dams that exhibited no ZIKV IF in the cervix, (D), only occasional macrophages were

946 noted, typically in the deeper stomal layer.

947 Figure 5. Pan flavivirus immunofluorescence (IF, Red: flavivirus; blue: DAPI) staining in

948 the placenta from a ZIKV RNA negative placenta from a dam infected with the FP isolate

949 (A) demonstrating a lack of ZIKV IF in villous placenta. ZIKV IF was noted in occasional

950 villous trophoblast in placenta from dams infected with the PR isolate $(B, C$; white

951 arrows) consistent with ZIKV infection of the syncytial layer. Infection of the amnion

952 epithelium was also observed (D; arrow). ZIKV IF was also observed in the

953 chorion/decidual layer of the fetal membranes in a dam infected with the PR isolate (E.

954 large arrow). Auto-fluorescing red blood cells are indicated with arrow heads.

955 Figure 6. Immunofluorescent staining in the placenta for macrophages (Red; DAPI:

956 Blue). In both FP isolate infected dams, only an occasional macrophage was observed

957 in the maternal and fetal compartments of the placenta (A: arrow). In the PR isolate

958 dams that were ZIKV IF and RNA positive, macrophages were more abundant, in

959 particular in the maternal compartment of the placenta (C: arrow). Arrowheads denote

960 auto-fluorescing red blood cells.

961 Figure 7. Immunofluorescent staining in the uterus for ZIKV (Red; DAPI: Blue). ZIKV IF

962 was not observed in the uterus, either endometrium or myometrium of FP isolate 
963 infected dams (A, B). In the PR isolate infected dams, ZIKV IF was not observed in the

964 myometrium and was occasionally observed in clusters of endometrial cells, (dashed

965 arrows, D).

966 Figure 8. Amino acid variance among Zika virus isolates. The amino acid sequences for

967 the FP (H/PF/2013; AHZ13508), PR (PRVABC59; AYI50388), and RIO (RIO-U1/2016;

968 AMD16557) complete polyproteins were aligned using the Clustal Omega algorithm in

969 Geneious Prime 2020.0.3 (www.geneious.com). Graphical representation of the ZIKV

970 genome as well as the resulting protein products is indicated. Amino acid variances are

971 highlighted in red with their position in the polyprotein noted by numerical annotation as

972 well as the nonstructural protein where they reside. The S139N mutation in the prM

973 protein is noted in all isolates for reference.

974

975

976

977

978

979

980

981

982

983

984

985

986

987

988 


\begin{tabular}{|c|c|c|c|c|c|c|c|c|}
\hline & \multicolumn{8}{|c|}{ Days Post-Initial Inoculation } \\
\hline Dam & -4 & 0 & 4 & 7 & 11 & 14 & 21 & 28 \\
\hline FP1 & $\Delta$ & $\mathrm{X}, \mathrm{O}$ & $\Delta$ & $\mathrm{X}, \mathrm{O}$ & $\Delta$ & $\Delta$ & $\Delta$ & $\Omega$ \\
\hline FP2 & $\Delta$ & $\mathrm{X}, \mathrm{O}$ & $\Delta$ & $\mathrm{X}, \mathrm{O}$ & $\Delta$ & $\Delta$ & $\Delta$ & $\Omega$ \\
\hline FP3 & $\Delta$ & $\mathrm{X}, \mathrm{O}$ & $\Delta$ & $\mathrm{X}, \mathrm{O}$ & $\Delta$ & $\mathrm{X}, \Delta$ & $\Delta$ & $\Omega$ \\
\hline PR1 & $\Delta$ & $\mathrm{X}, \mathrm{O}$ & $\Delta$ & $\mathrm{X}, \mathrm{O}$ & $\Delta$ & $\Delta$ & $\Delta$ & $\Omega$ \\
\hline PR2 & $\Delta$ & $\mathrm{X}, \mathrm{O}$ & $\Delta$ & $\mathrm{X}, \mathrm{O}$ & $\Delta$ & $\Delta$ & $\Delta$ & $\Omega$ \\
\hline PR3 & $\Delta$ & $\mathrm{X}, \mathrm{O}$ & $\Delta$ & $\mathrm{X}, \mathrm{O}$ & $\Delta$ & $\mathrm{X}, \Delta$ & $\Delta$ & $\Omega$ \\
\hline \multicolumn{9}{|c|}{$\begin{array}{l}\text { X: Vaginal inoculation with ZIKV infected }\left(1 \times 10^{6} \text { pfu) baboon semen }(1 \mathrm{~mL}) \text { French }\right. \\
\text { Polynesian ( } \mathrm{n}=3 \text {; FP1, FP2, FP3) or Puerto Rico isolate }(\mathrm{n}=3 \text {; PR1, PR2, PR3): } \\
\text { Inoculations repeated at } 7 \mathrm{~d} \text { intervals until evidence of viremia (qPCR) }\end{array}$} \\
\hline \multicolumn{9}{|c|}{ O: Blood and saliva samples } \\
\hline \multicolumn{9}{|c|}{$\Delta:$ Cervico-vaginal washings, blood and saliva samples } \\
\hline \multicolumn{9}{|c|}{$\begin{array}{l}\Omega: \text { Maternal/fetal tissues, cervico-vaginal washings, blood and saliva samples were } \\
\text { collected following euthanasia }\end{array}$} \\
\hline \multicolumn{9}{|c|}{$\begin{array}{l}\text { Baboon semen was obtained via electro-ejaculation. All procedures were performed } \\
\text { with IACUC approval. }\end{array}$} \\
\hline
\end{tabular}




\begin{tabular}{|c|c|c|c|}
\hline & Primers & $\begin{array}{l}\text { Genome } \\
\text { Position }\end{array}$ & Sequence (5`-3`) \\
\hline \multirow{3}{*}{1} & ZIKV 835 Forward & $835-857$ & TTGGTCATGATACTGCTGATTGC \\
\hline & ZIKV 911 Reverse & $890-911$ & CCTTCCACAAAGTCCCTATTGC \\
\hline & ZIKV 860-FAM Probe & $860-886$ & CGGCATACAGCATCAGGTGCATAGGAG \\
\hline \multirow{3}{*}{2} & ZIKV 1086 Forward & $1086-1102$ & CCGCTGCCCAACACAAG \\
\hline & ZIKV 1162 Reverse & $1162-1139$ & CCACTAACGTTCTTTTGCAGACAT \\
\hline & ZIKV 1107-FAM Probe & $1107-1137$ & AGCCTACCTTGACAAGCAGTCAGACACTCAA \\
\hline
\end{tabular}


Table 3. ZIKV RNA (log) - Maternal Reproductive Tissues and Maternal Lymph

\begin{tabular}{|c|c|c|c|c|c|c|c|}
\hline & \multicolumn{4}{|c|}{$\begin{array}{c}\text { Maternal Reproductive Tissues - ZIKV RNA } \\
(\text { (log) }\end{array}$} & \multicolumn{3}{|c|}{$\begin{array}{c}\text { Maternal Lymph Nodes - ZIKV RNA } \\
(\text { (log) }\end{array}$} \\
\hline \multicolumn{8}{|c|}{ FRENCH POLYNESIAN (FP) ISOLATE } \\
\hline Dam & Uterus & Cervix & Vagina & Ovary & Inguinal & Mesenteric & Axial \\
\hline FP1 & - & - & - & - & 2.5E05 & 3.3E06 & 1.0E05 \\
\hline FP2 & - & - & - & - & 7.6E05 & 2.0E05 & 5.4E05 \\
\hline FP3 & - & - & - & - & 7.7E03 & - & 5.0E03 \\
\hline \multicolumn{8}{|c|}{ PUERTO RICAN (PR) ISOLATE } \\
\hline PR1 & 3.2E03 & - & 6.9E03 & - & 2.7E03 & - & 4.1E03 \\
\hline PR2 & 4.7E04 & - & - & - & 2.7E05 & 5.8E05 & 3.2E05 \\
\hline PR3 & - & - & 2.8E03 & - & 1.2E04 & 7.1E04 & - \\
\hline - bel & iel of $d$ & & & & & & \\
\hline
\end{tabular}


Table 4. ZIKV RNA (log) - Placental Tissues

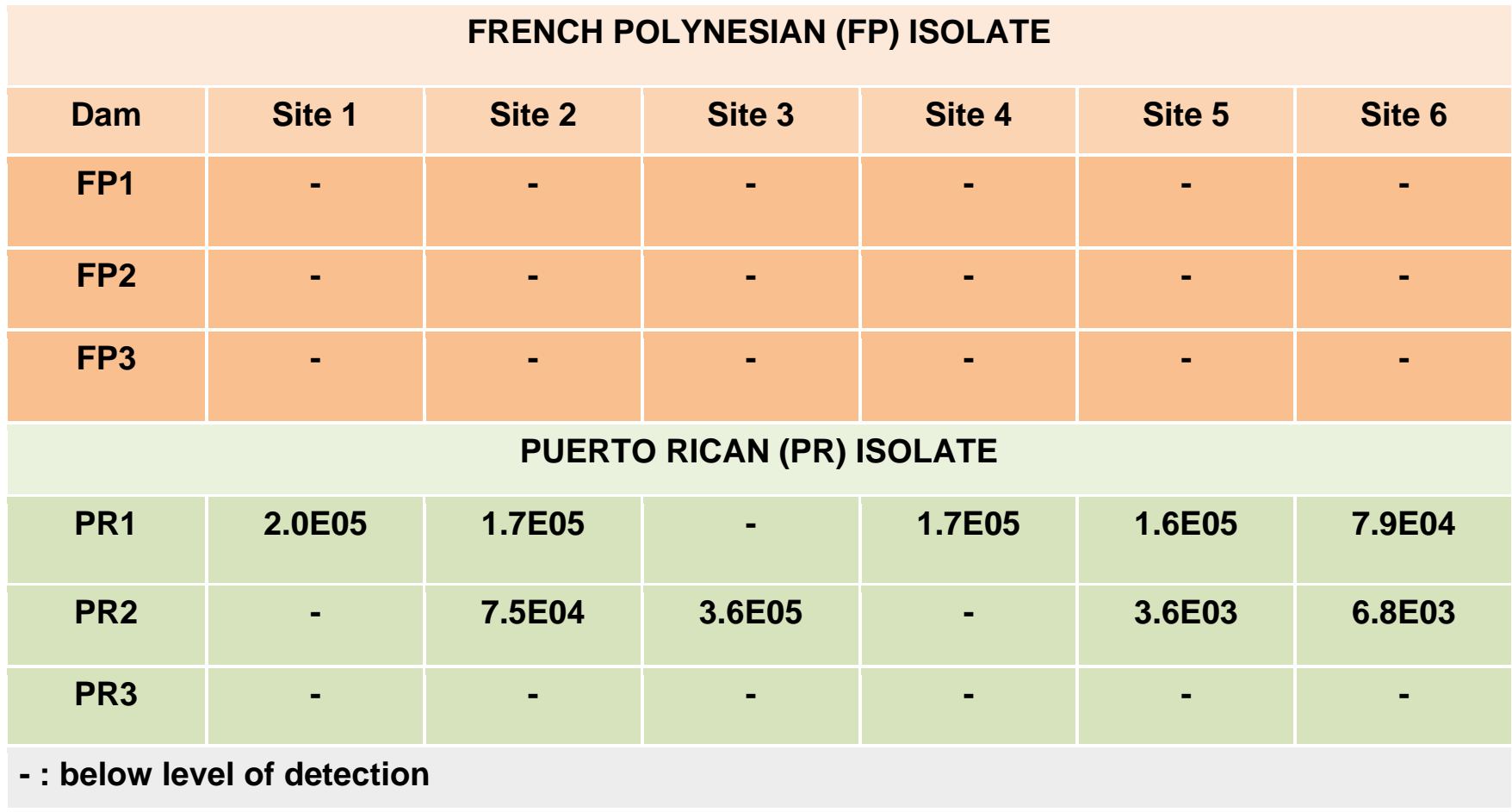

1042

1043

1044

1045

1046

1047

1048

1049

1050

1051

1052

1053

1054 

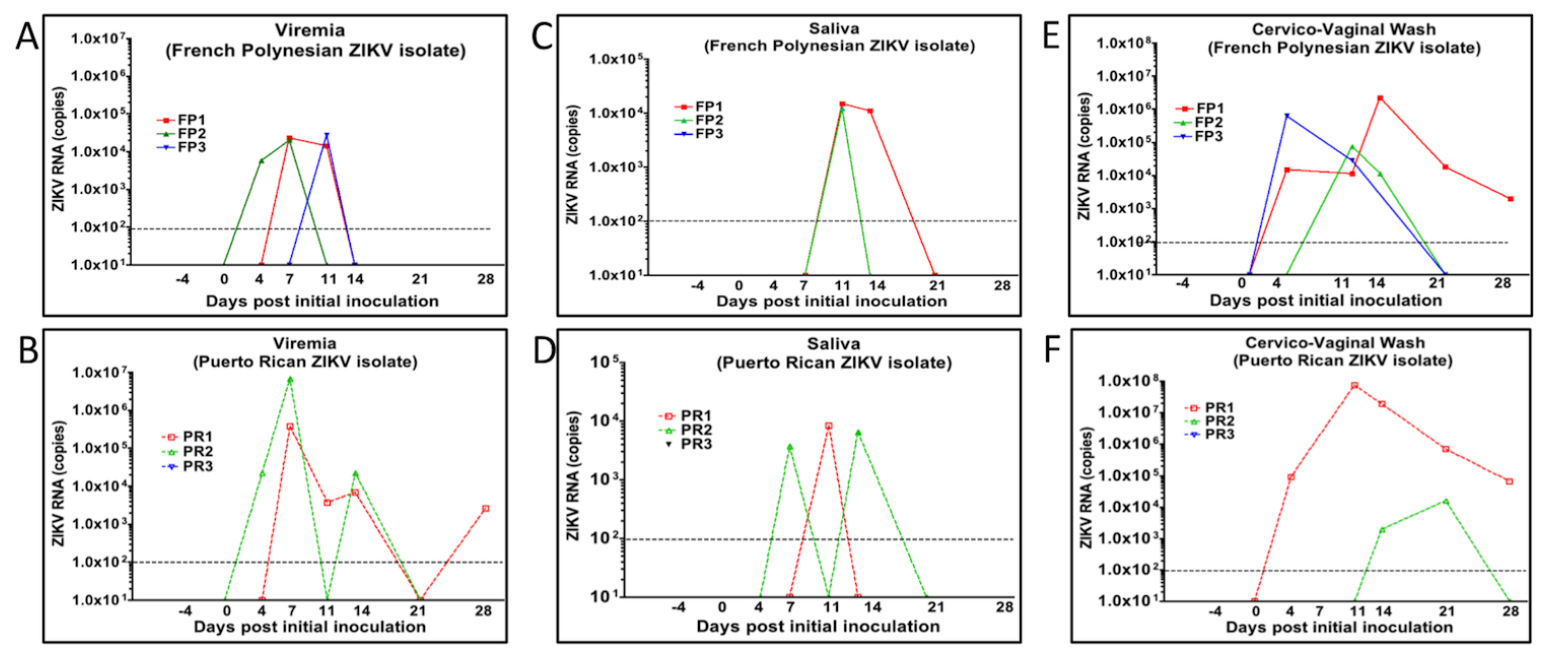

1058

FIGURE 2
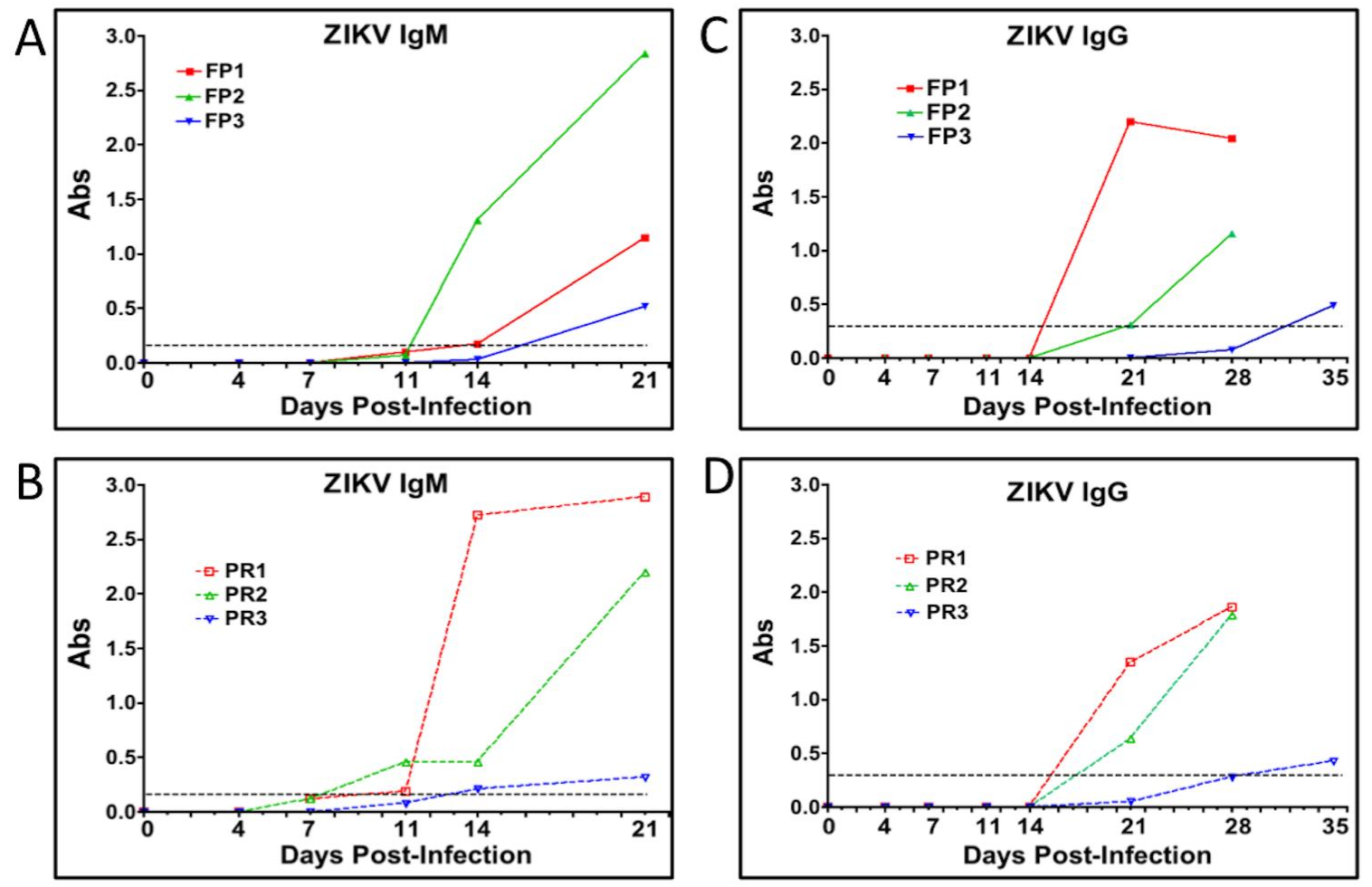
bioRxiv preprint doi: https://doi.org/10.1101/2020.01.10.902692; this version posted January 11, 2020. The copyright holder for this preprint (which was not certified by peer review) is the author/funder. All rights reserved. No reuse allowed without permission.

1063 FIGURE 3
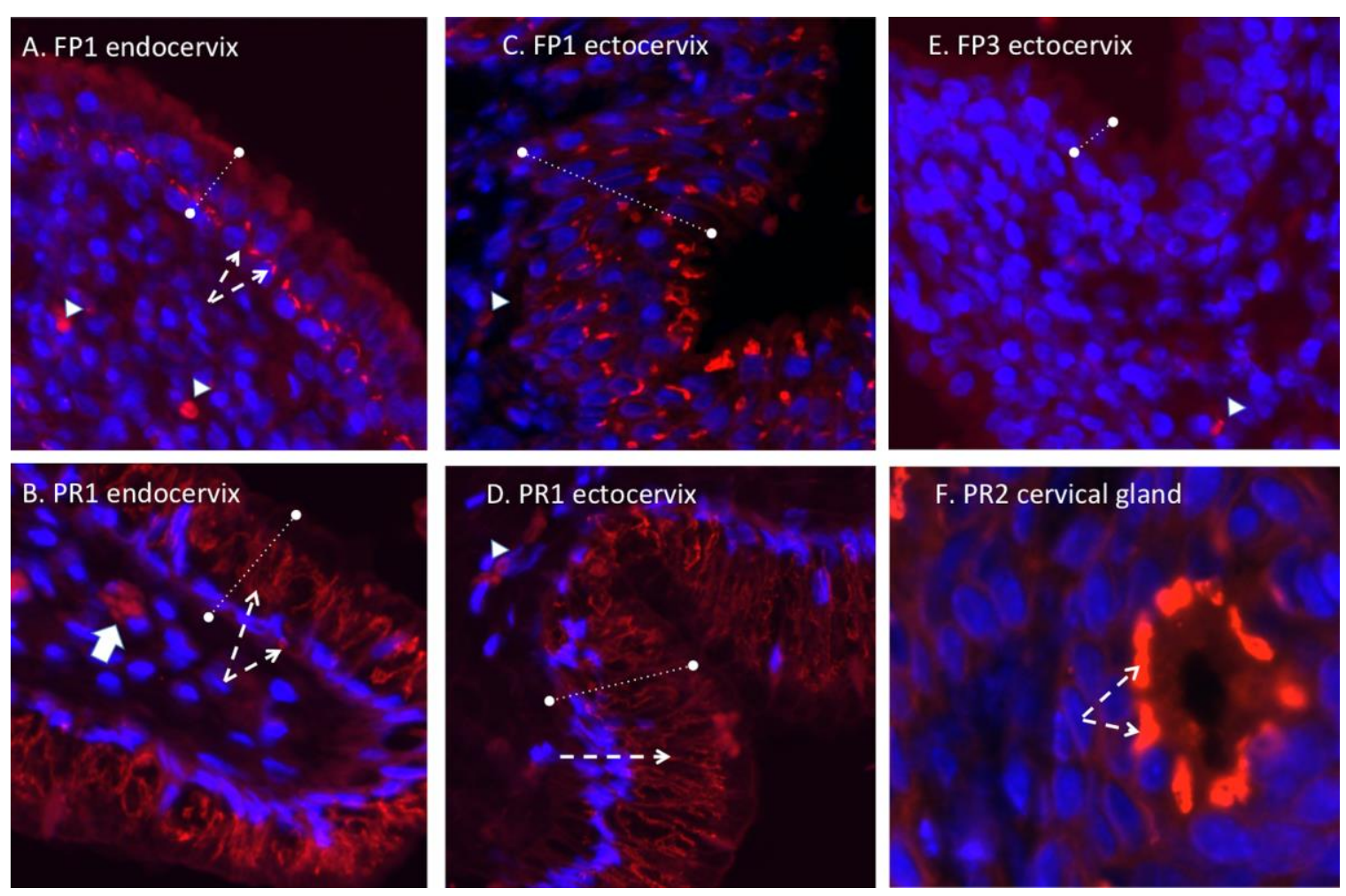

1065 


\section{FIGURE 4}
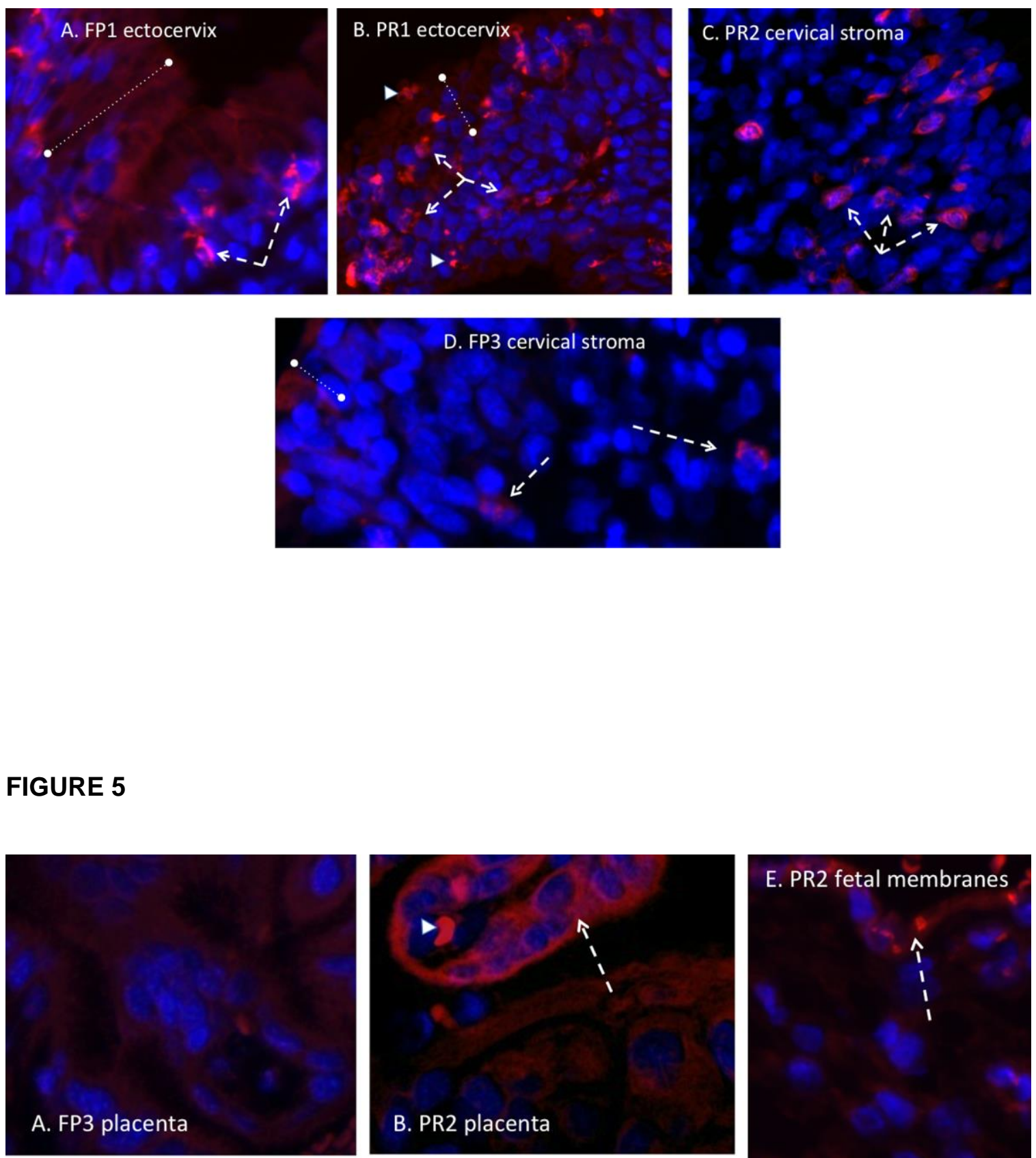

\section{PR1 placenta}
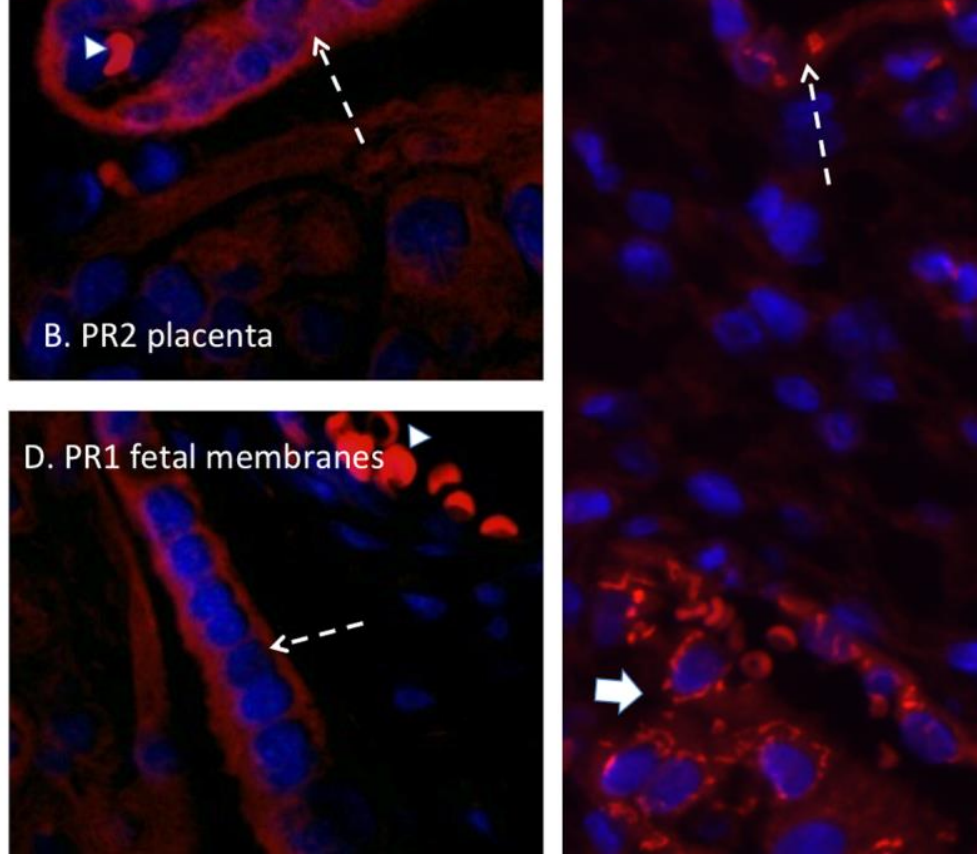
bioRxiv preprint doi: https://doi.org/10.1101/2020.01.10.902692; this version posted January 11, 2020. The copyright holder for this preprint (which was not certified by peer review) is the author/funder. All rights reserved. No reuse allowed without permission.

1073 FIGURE 6
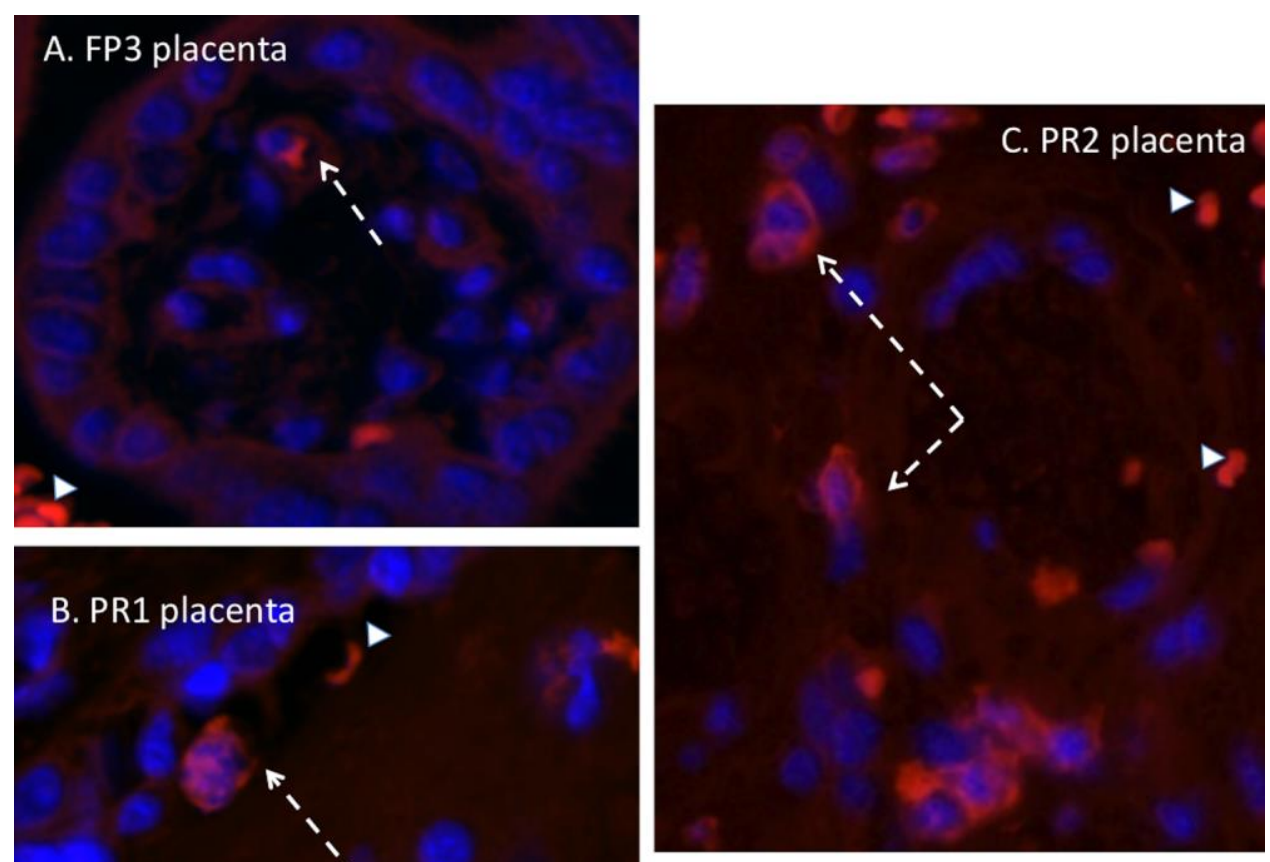

1074

\section{B. PR1 placenta}

F

1075

1076

1077

1078

1079

1080

1081 
bioRxiv preprint doi: https://doi.org/10.1101/2020.01.10.902692; this version posted January 11, 2020. The copyright holder for this preprint (which was not certified by peer review) is the author/funder. All rights reserved. No reuse allowed without permission.

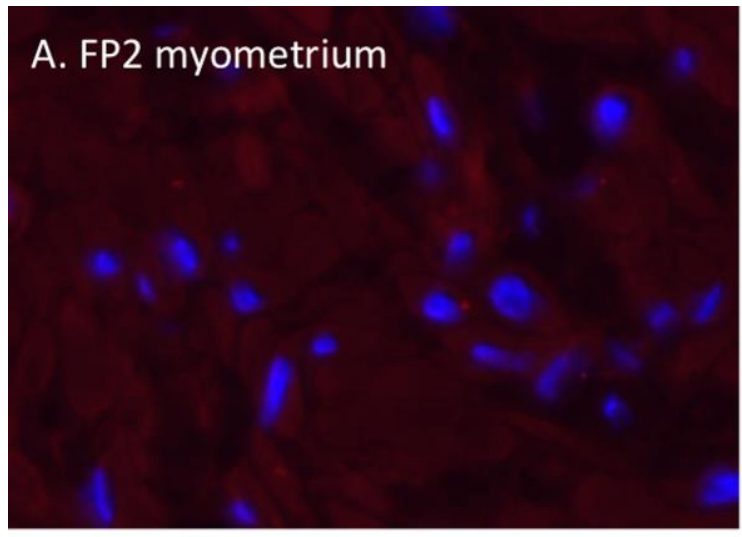

\section{PR1 myometrium}

\section{B. FP2 endometrium}

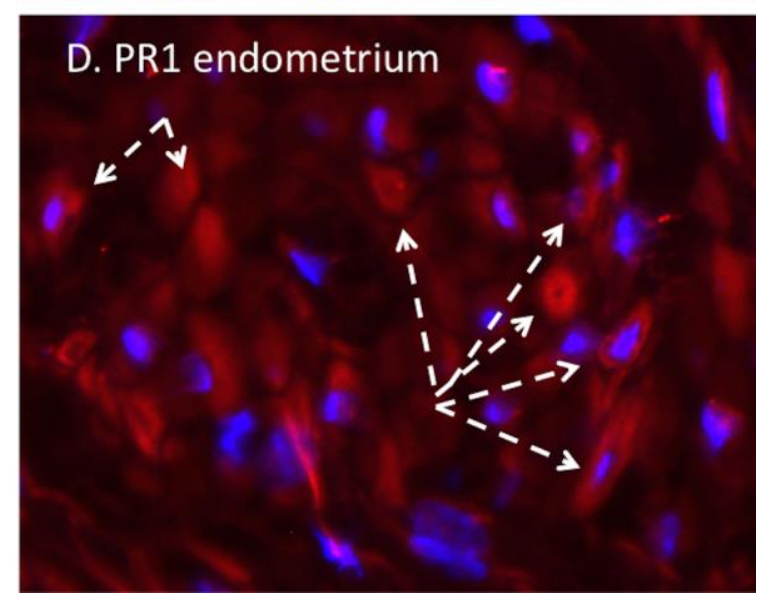

1084

1085

FIGURE 8

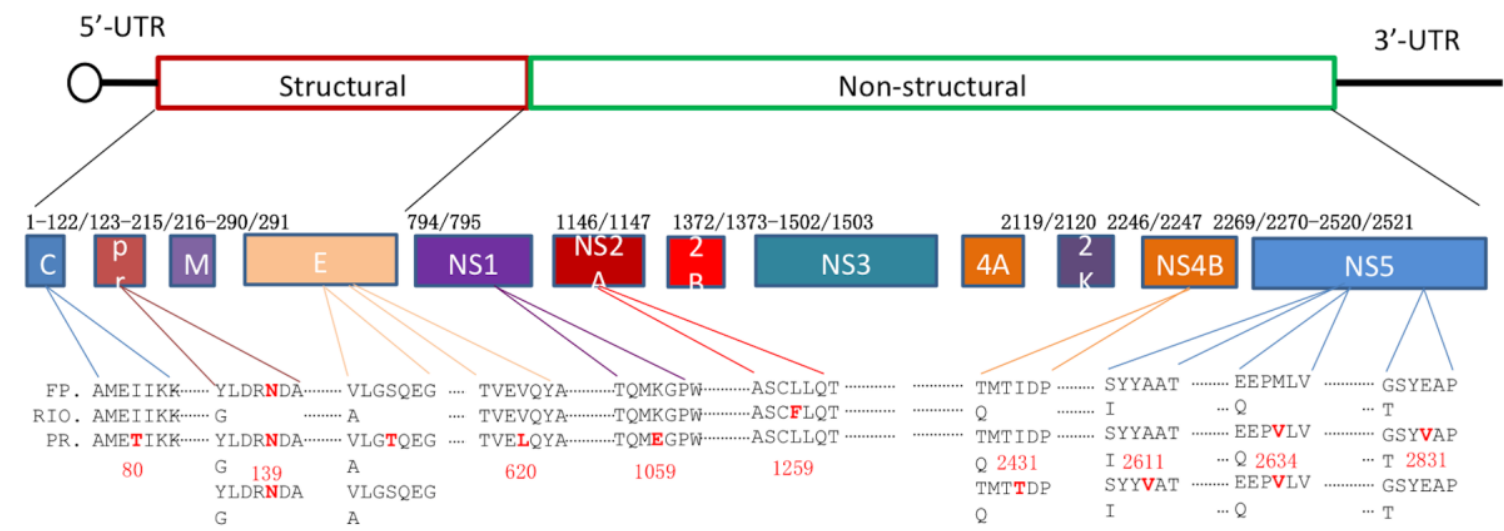

